\title{
Strategies to Prevent Surgical Site Infections in Acute Care Hospitals: 2014 Update
}

\author{
Deverick J. Anderson, MD, MPH; ${ }^{1}$ Kelly Podgorny, DNP, MS, RN; ${ }^{2}$ Sandra I. Berríos-Torres, MD; ${ }^{3}$ \\ Dale W. Bratzler, DO, MPH; ${ }^{4}$ E. Patchen Dellinger, MD; ${ }^{5}$ Linda Greene, RN, MPS, CIC; ${ }^{6}$ \\ Ann-Christine Nyquist, MD, MSPH; ${ }^{7}$ Lisa Saiman, MD, MPH; ${ }^{8}$ Deborah S. Yokoe, MD, MPH; ${ }^{9}$ \\ Lisa L. Maragakis, MD, MPH; ${ }^{10}$ Keith S. Kaye, MD, $\mathrm{MPH}^{11}$
}

\section{PURPOSE}

Previously published guidelines are available that provide comprehensive recommendations for detecting and preventing healthcare-associated infections (HAIs). The intent of this document is to highlight practical recommendations in a concise format designed to assist acute care hospitals in implementing and prioritizing their surgical site infection (SSI) prevention efforts. This document updates "Strategies to Prevent Surgical Site Infections in Acute Care Hospitals," published in 2008. This expert guidance document is sponsored by the Society for Healthcare Epidemiology of America (SHEA) and is the product of a collaborative effort led by SHEA, the Infectious Diseases Society of America (IDSA), the American Hospital Association (AHA), the Association for Professionals in Infection Control and Epidemiology (APIC), and The Joint Commission, with major contributions from representatives of a number of organizations and societies with content expertise. The list of endorsing and supporting organizations is presented in the introduction to the 2014 updates. ${ }^{2}$

\section{SECTION 1: RATIONALE AND STATEMENTS}

\section{OF CONCERN}

I. SSIs are common complications in acute care facilities

A. SSIs occur in $2 \%-5 \%$ of patients undergoing inpatient surgery. ${ }^{3,4}$

B. Approximately $160,000-300,000$ SSIs occur each year in the United States. ${ }^{5,6}$

C. SSI is now the most common and most costly HAI.-9

II. Outcomes associated with SSI

A. Up to $60 \%$ of SSIs have been estimated to be pre- ventable by using evidence-based guidelines. ${ }^{10,11}$

B. SSIs account for $20 \%$ of all HAIs in hospitalized patients. ${ }^{12}$

C. Each SSI is associated with approximately 7-11 additional postoperative hospital-days. ${ }^{3,9,13,14}$

D. Patients with an SSI have a 2-11-times higher risk of death compared with operative patients without an SSI. ${ }^{15,16}$

1. Seventy-seven percent of deaths in patients with SSI are directly attributable to SSI. ${ }^{17}$

E. Attributable costs of SSI vary depending on the type of operative procedure and the type of infecting pathogen. . $^{14,16,18-25}$

1. SSIs are believed to account for $\$ 3.5$ billion to $\$ 10$ billion annually in healthcare expenditures using the CPI (consumer price index for inpatient hospital services with all cost estimates adjusted for 2007 dollars). ${ }^{6}$

\section{SECTION 2: BACKGROUND-STRATEGIES TO DETECT SSI}

I. Surveillance definitions

A. The Centers for Disease Control and Prevention's (CDC's) National Healthcare Safety Network (NHSN) definitions for SSI are widely used for public reporting, interfacility comparison, and pay-for-performance comparisons. ${ }^{26}$

B. SSIs are classified (Figure 1) as follows:

1. Superficial incisional (involving only skin or subcutaneous tissue of the incision).

Affiliations: 1. Duke University Medical Center, Durham, North Carolina; 2. The Joint Commission, Oakbrook Terrace, Illinois; 3. Centers for Disease Control and Prevention, Atlanta, Georgia; 4. University of Oklahoma Health Sciences Center, Oklahoma City, Oklahoma; 5. University of Washington Medical Center, Seattle, Washington; 6. Highland Hospital and University of Rochester Medical Center, Rochester, New York; 7. Children's Hospital Colorado and University of Colorado School of Medicine, Aurora, Colorado; 8. Columbia University Medical Center, New York, New York; 9. Brigham and Women's Hospital and Harvard Medical School, Boston, Massachusetts; 10. Johns Hopkins University School of Medicine, Baltimore, Maryland; 11. Detroit Medical Center and Wayne State University, Detroit, Michigan.

Received February 12, 2014; accepted February 17, 2014; electronically published May 5, 2014.

Infect Control Hosp Epidemiol 2014;35(6):605-627

(c) 2014 by The Society for Healthcare Epidemiology of America. All rights reserved. 0899-823X/2014/3506-0001\$15.00. DOI: 10.1086/676022 


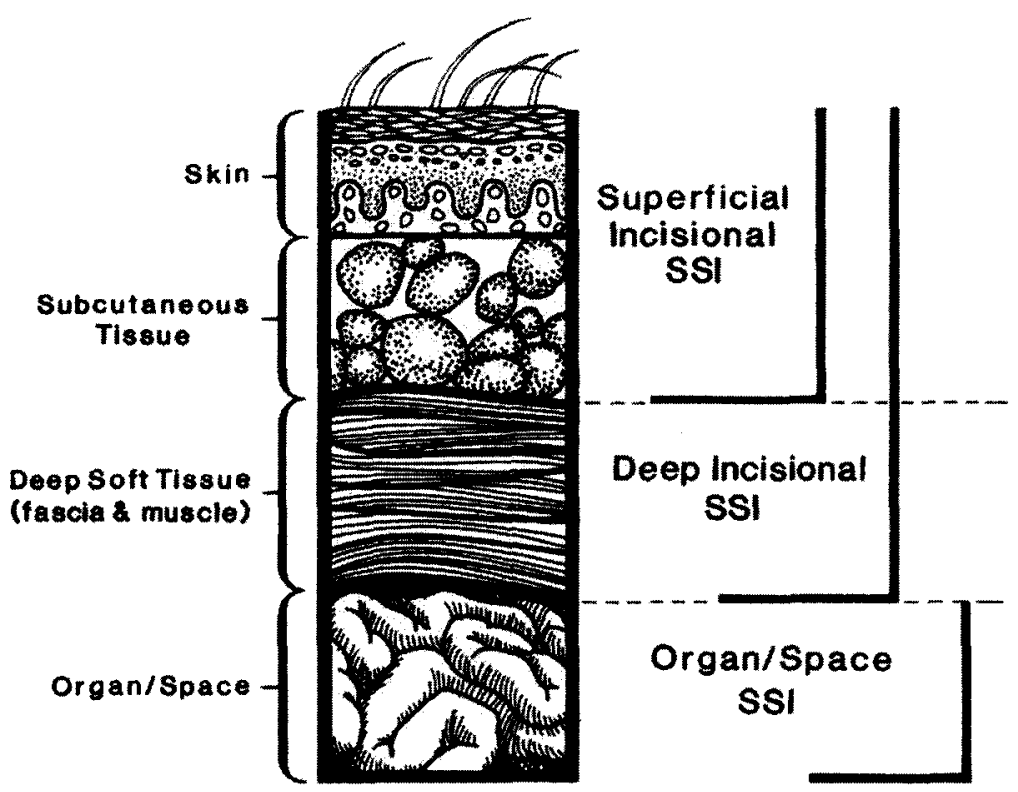

FIGURE 1. Centers for Disease Control and Prevention's National Healthcare Safety Network classification for surgical site infection (SSI). ${ }^{215}$

2. Deep incisional (involving fascia and/or muscular layers).

a. Deep incision primary (DIP)—SSI identified in a primary incision in a patient who has had an operation with 1 or more incisions.

b. Deep incision secondary (DIS) - SSI identified in a secondary incision in a patient who has had an operation with more than 1 incision.

3. Organ/space (involving any part of the body opened or manipulated during the procedure, excluding skin incision, fascia, or muscle layers).

II. Methods for surveillance of SSI

A. The direct method with daily observation of the surgical site by the physician, physician extender, registered nurse, or infection prevention and control (IPC) professional starting 24-48 hours postoperatively is the most accurate method of surveillance. ${ }^{13,27-29}$

1. While the direct method is used as the gold standard for studies, it is rarely used in practice because of its resource utilization requirements and impracticality.

B. The indirect method of SSI surveillance consists of a combination of the following:

1. Review of microbiology reports and patient medical records.

2. Surgeon and/or patient surveys.

3. Screening for readmission and/or return to the operating room.

4. Other information, such as coded diagnoses, coded procedures, operative reports, or antimicrobials ordered.

C. The indirect method of SSI surveillance is less timeconsuming and can be readily performed by IPC per- sonnel during surveillance rounds.

D. The indirect method of SSI surveillance is both reliable (sensitivity, 84\%-89\%) and specific (specificity, 99.8\%) compared with the gold standard of direct surveillance. ${ }^{30,31}$ Components of the indirect methods that were associated with highest sensitivities included review of nursing notes, International Classification of Diseases, Ninth Revision codes, and antimicrobials used.

E. Indirect methods for SSI surveillance are not reliable for surveillance of superficial incisional infections, particularly those occurring postdischarge. ${ }^{32}$

F. Automated data systems can be used to broaden SSI surveillance.

1. SSI surveillance can be expanded by utilizing hospital databases that include administrative claims data (including diagnosis and procedure codes), antimicrobial-days, readmission to the hospital, and return to the operating room and/or by implementing a system that imports automated microbiologic culture data, surgical procedure data, and general demographic information into a single surveillance database..$^{33-35}$

2. These methods improve the sensitivity of indirect surveillance for detection of SSI and reduce the effort of the infection preventionist. ${ }^{33}$

3. Medicare claims data can be used to enhance traditional surveillance methods for SSI and to identify hospitals with unusually high or low rates of SSI. ${ }^{36,37}$

4. Use of administrative data can increase the efficiency of SSI reporting and validation. ${ }^{38}$

III. Postdischarge surveillance

A. Over the past 3 decades, advances in medical technology and changes in payment arrangements have increasingly shifted performance of surgical procedures from 
the acute care setting to the ambulatory (free-standing or hospital-affiliated) outpatient care setting. ${ }^{39-41}$

B. Concurrently, postoperative hospital length of stay has steadily declined. ${ }^{42}$ These trends highlight the increasing importance of postdischarge surveillance, without which SSI rates will be underestimated ${ }^{43}$ and opportunities for improvements in healthcare delivery, patient safety, and SSI prevention will be missed.

C. The proportion of SSIs detected through postdischarge surveillance can vary by surveillance method, operative setting, type of SSI, and surgical procedure.

1. No standardized or reliable method for postdischarge surveillance has been established. ${ }^{34,44-48}$ Postdischarge surveillance based on surgeon and patient questionnaire results have been shown to have poor sensitivity and specificity. $44,49-51$

2. The ambulatory care setting represents a challenge because patients do not return to it for routine postoperative care or for management of complications. ${ }^{41}$ Research is needed to better understand how definitions and postdischarge surveillance protocols developed for the acute care setting can be translated to the ambulatory care setting.

3. Superficial incisional SSIs are most commonly detected and managed in the outpatient setting. In contrast, deep incisional and organ/space infections typically require readmission to the hospital for management. ${ }^{32}$

4. In the Netherlands, the proportion of deep SSIs identified after discharge from the hospital ranged from $6 \%$ for colon resections to $88 \%$ for knee arthroplasties. ${ }^{43}$ The differences between these procedures could be explained by potential differences in both wound contamination class and the duration of postdischarge surveillance (30 days versus 1 year for an implant-related procedure). A pilot study in general surgery reported that $10.5 \%$ of SSIs following colon procedures were identified after discharge from the hospital..$^{52}$

5. By improving completeness of reporting, the overall institutional SSI rate typically increases after postdischarge surveillance methods are implemented regardless of which method is used. ${ }^{43,44,53}$

a. To improve interfacility comparisons and minimize potential bias introduced by differences in postdischarge surveillance methods, national public reporting focuses on nonsuperficial incisional SSIs detected during hospitalization for the index procedure or after discharge and requiring readmission for management. ${ }^{41,54,55}$

\section{SECTION 3: BACKGROUND-STRATEGIES}

TO PREVENT SSI

I. Summary of existing guidelines, recommendations, and requirements
A. CDC and Healthcare Infection Control Practices Advisory Committee (HICPAC) guidelines

1. The most recently published guideline for prevention of SSIs was released in 1999 by Mangram et al. ${ }^{17}$ The $\mathrm{CDC}$ and HICPAC are currently working on an updated version of the guideline with a projected publication date in mid-2014.

B. National Institute for Health and Clinical Excellence (NICE)-United Kingdom

1. NICE published guidelines for the prevention and treatment of SSI in $2008 .^{56}$

C. Surgical Infection Prevention (SIP) Project

1. The Centers for Medicare \& Medicaid Services (CMS) created the SIP project in 2002.

a. After review of published guidelines, an expert panel identified 3 performance measures for quality improvement related to antimicrobial prophylaxis: ${ }^{57,58}$

$i$. Delivery of intravenous antimicrobial prophylaxis within 1 hour before incision ( 2 hours are allowed for the administration of vancomycin and fluoroquinolones).

ii. Use of an antimicrobial prophylactic agent consistent with published guidelines.

iii. Discontinuation of the prophylactic antimicrobial agent within 24 hours after surgery (discontinuation within 48 hours is allowable for cardiothoracic procedures in adult patients).

b. The SIP project focused on 7 procedures: abdominal hysterectomy, vaginal hysterectomy, hip arthroplasty, knee arthroplasty, cardiac surgery, vascular surgery, and colorectal surgery.

c. Many hospitals that implemented and improved compliance with SIP performance measures decreased their rates of SSI. ${ }^{59}$

D. Surgical Care Improvement Project (SCIP)

1. The SCIP, a multiagency collaboration created in 2003 , is an extension of SIP.

2. In addition to the 3 performance measures of SIP, the SCIP also focuses on 3 additional evidence-supported process measures to prevent SSIs and expanded the types of operations eligible for the performance measures. ${ }^{58}$

a. Proper hair removal: no hair removal, although hair removal with clippers or the depilatory method is considered appropriate. Use of razors is considered inappropriate with exception of use on the scrotal area or on the scalp after a traumatic head injury. Because of near-universal compliance with this performance measure, CMS retired the measure in 2012.

b. Controlling blood glucose during the immediate postoperative period for cardiac surgery patients: controlled 6 AM blood glucose $(200 \mathrm{mg} / \mathrm{dL}$ or lower) on postoperative days 1 and 2, with the procedure day being postoperative day 0 . In 2014, 
this measure will be revised to assess glucose control $(180 \mathrm{mg} / \mathrm{dL}$ or lower $)$ in cardiac surgery patients in the time frame of 18-24 hours after anesthesia end time. ${ }^{60,61}$

c. Maintenance of perioperative normothermia in surgical patients who have anesthesia duration of at least 60 minutes.

E. Institute for Healthcare Improvement (IHI)

1. The IHI created a nationwide quality improvement project to improve outcomes in hospitalized patients. $^{62,63}$

2. The IHI recommends the same 6 preventive measures recommended by the SCIP and has included these in the 100,000 and 5 Million Lives Campaigns. ${ }^{62,63}$

F. The Joint Commission National Patient Safety Goals

1. The Joint Commission's National Patient Safety Goal 07.05.01 includes several evidence-based practices for prevention of SSI. ${ }^{64}$

G. Federal requirements

1. CMS

a. In accordance with the Deficit Reduction Act of 2005, hospitals that are paid by Medicare under the Acute Care Inpatient Prospective Payment System receive their full Medicare annual payment update only if they submit required quality measure information to CMS.

b. CMS now requires hospitals to submit data on 7 SCIP measures as a part of the Hospital Inpatient Quality Reporting (IQR) system. ${ }^{65}$ Three of these measures focus on prevention of SSI (antimicrobial prophylaxis provided within 1 hour of incision, antimicrobial selection, and cardiac surgery perioperative glucose control). In addition, CMS now requires hospitals to report SSI rates for patients undergoing abdominal hysterectomy and colorectal surgery through NHSN. ${ }^{65}$

c. Actual rates of performance on SCIP measures now impacts hospital payment under the Value-Based Purchasing (VBP) program. Current benchmarks identified for the VBP score that is used to modify a hospital's base operating diagnosis-related group payment are at or near $100 \% .65$

\section{Infrastructure requirements}

\section{A. Trained personnel}

1. Infection preventionists must (1) be specifically trained in methods of SSI surveillance, (2) have knowledge of and the ability to prospectively apply the CDC/NHSN definitions for SSI, (3) possess basic computer and mathematical skills, and (4) be adept at providing feedback and education to healthcare personnel when appropriate. ${ }^{17}$

B. Education

1. Regularly provide education to surgeons and perioperative personnel through continuing education activities directed at minimizing perioperative SSI risk through implementation of recommended process measures.

a. Several educational components can be combined into concise, efficient, and effective recommendations that are easily understood and remembered. ${ }^{67}$

b. Provide education regarding the outcomes associated with SSI, risks for SSI, and methods to reduce risk to all patients, patients' families, surgeons, and perioperative personnel.

c. Education for patients and patients' families is an effective method to reduce risk associated with intrinsic patient-related SSI risk factors. ${ }^{68,69}$

C. Computer-assisted decision support and automated reminders

1. Several institutions have successfully employed computer-assisted decision support methodology to improve the rate of appropriate administration of antimicrobial prophylaxis (including redosing during prolonged cases). ${ }^{70-73}$

2. Computer-assisted decision support, however, is potentially expensive, can be time-consuming to implement, and in a single study was reported to initially increase the rate of adverse drug reactions. ${ }^{74}$

3. Institutions must appropriately validate computer-assisted decision support systems after implementation.

D. Utilization of automated data

1. Install information technology infrastructure to facilitate data transfer, receipt, and organization to aid with tracking of process and outcome measures.

\section{SECTION 4: RECOMMENDED STRATEGIES FOR SSI PREVENTION}

Recommendations are categorized as either (1) basic practices that should be adopted by all acute care hospitals or (2) special approaches that can be considered for use in locations and/or populations within hospitals when HAIs are not controlled by use of basic practices. Basic practices include recommendations where the potential to impact HAI risk clearly outweighs the potential for undesirable effects. Special approaches include recommendations where the intervention is likely to reduce HAI risk but where there is concern about the risks for undesirable outcomes resulting from the intervention, where the quality of evidence is low, or where evidence supports the impact of the intervention in select settings (eg, during outbreaks) or for select patient populations. Hospitals can prioritize their efforts by initially focusing on implementation of the prevention approaches listed as basic practices. If HAI surveillance or other risk assessments suggest that there are ongoing opportunities for improvement, hospitals should then consider adopting some or all of the prevention approaches listed as special approaches. These can be implemented in specific locations or patient populations or can be implemented hospital-wide, depending on outcome data, risk assessment, and/or local requirements. Each infec- 
TABLE 1. Grading of the Quality of Evidence

\begin{tabular}{|c|c|}
\hline Grade & Definition \\
\hline I. High & $\begin{array}{l}\text { Highly confident that the true effect lies close to that of the estimated size and direction of the } \\
\text { effect. Evidence is rated as high quality when there is a wide range of studies with no major } \\
\text { limitations, there is little variation between studies, and the summary estimate has a narrow } \\
\text { confidence interval. }\end{array}$ \\
\hline II. Moderate & $\begin{array}{l}\text { The true effect is likely to be close to the estimated size and direction of the effect, but there is } \\
\text { a possibility that it is substantially different. Evidence is rated as moderate quality when there } \\
\text { are only a few studies and some have limitations but not major flaws, there is some variation } \\
\text { between studies, or the confidence interval of the summary estimate is wide. }\end{array}$ \\
\hline III. Low & $\begin{array}{l}\text { The true effect may be substantially different from the estimated size and direction of the effect. } \\
\text { Evidence is rated as low quality when supporting studies have major flaws, there is important } \\
\text { variation between studies, the confidence interval of the summary estimate is very wide, or } \\
\text { there are no rigorous studies, only expert consensus. }\end{array}$ \\
\hline
\end{tabular}

Note. Based on Grades of Recommendation, Assessment, Development, and Evaluation (GRADE) ${ }^{234}$ and the Canadian Task Force on Preventive Health Care. ${ }^{235}$

tion prevention recommendation is given a quality-of-evidence grade (see Table 1).

I. Basic practices for preventing SSI: recommended for all acute care hospitals

1. Administer antimicrobial prophylaxis according to evidence-based standards and guidelines (quality of evidence: I). ${ }^{17,75,76}$

a. Begin administration within 1 hour before incision to maximize tissue concentration. ${ }^{57,58}$ Administering agent closer than 1 hour is effective, and some studies show superior efficacy for administration between 0 and 30 minutes prior to incision compared with administration between 30 and 60 minutes. ${ }^{77,78}$

$i$. Two hours are allowed for the administration of vancomycin and fluoroquinolones.

ii. Many experts believe that antimicrobials should be infused prior to inflation of tourniquets in procedures using "bloodless" techniques, although data are insufficient to support this recommendation. ${ }^{79,80}$

b. Select appropriate agents on the basis of the surgical procedure, the most common pathogens causing SSIs for a specific procedure, and published recommendations. ${ }^{76}$

c. Discontinue agent within 24 hours after surgery. ${ }^{76}$

i. Although guidelines suggest stopping the antimicrobial agent within 24 hours of surgery, there is no evidence that agents given after closure contribute to efficacy, and they do contribute to increased resistance ${ }^{81,82}$ and the risk of Clostridium difficile disease. ${ }^{83}$

d. Adjust dosing on the basis of patient weight ${ }^{76}$ for example:

i. Use $30 \mathrm{mg} / \mathrm{kg}$ for pediatric patients, $2 \mathrm{~g}$ of cefazolin for patients weighing $80 \mathrm{~kg}$ or more, and 3 $\mathrm{g}$ for patients weighing $120 \mathrm{~kg}$ or more.

ii. Vancomycin should be dosed at $15 \mathrm{mg} / \mathrm{kg}$.

iii. Gentamicin should be dosed at $5 \mathrm{mg} / \mathrm{kg}$ for adult patients and $2.5 \mathrm{mg} / \mathrm{kg}$ for pediatric patients.

(a) For morbidly obese patients receiving gentamicin, the weight used for dose calculation should be the ideal weight plus $40 \%$ of the excess weight.

e. Redose prophylactic antimicrobial agents for long procedures and in cases with excessive blood loss during the procedure. ${ }^{76}$

i. Prophylactic antimicrobials should be redosed at intervals of 2 half-lives (measured from time the preoperative dose was administered) in cases that exceed this time.

f. Use a combination of parenteral antimicrobial agents and oral antimicrobials to reduce the risk of SSI following colorectal procedures. ${ }^{84-91}$

$i$. The additional SSI reduction achieved with mechanical bowel preparation has not been studied, but the data supporting use of oral antimicrobials have all been generated in combination with mechanical bowel preparation.

ii. Mechanical bowel preparation without oral antimicrobials does not decrease the risk of SSI. ${ }^{92}$

2. Do not remove hair at the operative site unless the presence of hair will interfere with the operation. Do not use razors (quality of evidence: II). ${ }^{17,93}$

a. If hair removal is necessary, remove hair outside the operating room using clippers or a depilatory agent.

3. Control blood glucose during the immediate postoperative period for cardiac surgery patients ${ }^{58}$ (quality of evidence: I) and noncardiac surgery patients ${ }^{94-98}$ (quality of evidence: II).

a. Maintain postoperative blood glucose of $180 \mathrm{mg} / \mathrm{dL}$ or lower.

i. The recommendation of maintaining postoperative blood glucose less than $200 \mathrm{mg} / \mathrm{dL}$ at 6 AM on postoperative days 1 and 2 is being replaced. In 2014, this measure will be revised in the SCIP to assess 
glucose control $(180 \mathrm{mg} / \mathrm{dL}$ or lower) in cardiac surgery patients in the time frame of 18-24 hours after anesthesia end time. Several societies, experts, and the National Quality Forum support this new recommendation. ${ }^{60,61,99,100}$

b. Intensive postoperative glucose control (targeting levels less than $110 \mathrm{mg} / \mathrm{dL}$ ) has not been shown to reduce the risk of SSI and may actually lead to higher rates of adverse outcomes, including stroke and death. ${ }^{101}$

4. Maintain normothermia (temperature of $35.5^{\circ} \mathrm{C}$ or more) during the perioperative period (quality of evidence: I).

a. Even mild degrees of hypothermia can increase SSI rates. Hypothermia may directly impair neutrophil function or impair it indirectly by triggering subcutaneous vasoconstriction and subsequent tissue hypoxia. In addition, hypothermia may increase blood loss, leading to wound hematomas or need for transfusion, both of which can increase rates of SSI. ${ }^{102}$

b. Randomized controlled trials have shown the benefits of both preoperative and intraoperative warming to reduce SSI rates and to reduce intraoperative blood loss. ${ }^{103-105}$

5. Optimize tissue oxygenation by administering supplemental oxygen during and immediately following surgical procedures involving mechanical ventilation (quality of evidence: I).

a. Supplemental oxygen is most effective when combined with additional strategies to improve tissue oxygenation, including maintenance of normothermia and appropriate volume replacement. The available evidence is in patients undergoing surgery with general anesthesia using mechanical ventilation. ${ }^{106-108}$

$i$. Seven randomized clinical trials have been published comparing $80 \%$ with $30 \%-35 \% \mathrm{FiO}_{2}$ (4 with nitrogen ${ }^{106-109}$ and 3 with nitrous oxide ${ }^{110-112}$ ) in patients undergoing general anesthesia with intraoperative mechanical ventilation and postoperative oxygen delivered for 2-6 hours via a nonrebreathing mask.

ii. Three trials in patients undergoing elective colorectal resection ${ }^{106,107,111}$ and 1 each in open appendectomy ${ }^{108}$ and total gastrectomy with esophagojejunal anastomosis ${ }^{112}$ reported an approximate $40 \%$ decrease in the rate of SSI. Three of the studies reported protocols that included maintenance of perioperative normothermia and liberal fluid replacement. ${ }^{106-108}$

iii. Two trials in mixed surgical populations undergoing emergency or elective laparotomy for gastrointestinal, gynecologic, or urologic procedures reported different results. ${ }^{109,110}$

(a) The large multicenter trial that restricted perioperative fluid replacement reported no dif- ference. ${ }^{109} \mathrm{~A}$ follow-up study performed in this population noted that patients undergoing cancer surgery who received $80 \% \mathrm{FiO}_{2}$ had higher rates of mortality than patients undergoing cancer surgery who received $30 \%$ $\mathrm{FiO}_{2}{ }^{113}$

(b) The smaller trial without standardized protocols for perioperative normothermia or volume replacement reported an increase in SSIs. ${ }^{110}$ In this study, the $80 \% \mathrm{FiO}_{2}$ group had a significantly higher proportion of patients with high body mass index (more than 30 ), higher blood loss, more crystalloid infused, and longer operations. This group also had 5 patients who remained intubated postoperatively (vs 1 in the $35 \%$ group). Postoperative intubation was predictive of SSI.

b. A meta-analysis of 5 of the above-referenced studies concluded that perioperative supplemental oxygen led to a relative risk (RR) reduction of $25 \%$ for SSI. ${ }^{114}$

6. Use alcohol-containing preoperative skin preparatory agents if no contraindication exists (quality of evidence: I).

a. Alcohol is highly bactericidal and effective for preoperative skin antisepsis but does not have persistent activity when used alone. Rapid, persistent, and cumulative antisepsis can be achieved by combining alcohol with chlorhexidine gluconate or an iodophor. ${ }^{115}$ $i$. Alcohol is contraindicated for certain procedures, including procedures in which the preparatory agent may pool or not dry (eg, involving hair) due to fire risk. Alcohol may also be contraindicated for procedures involving mucosa, cornea, or ear.

b. The most effective disinfectant to combine with alcohol is unclear.

i. A recent trial of 849 patients undergoing cleancontaminated surgery randomized patients to preoperative skin antisepsis with chlorhexidinealcohol or povidone-iodine. ${ }^{116}$ The overall rate of SSI was significantly lower in the chlorhexidinealcohol group than in the povidone-iodine group (9.5\% vs $16 \%[P=.004]$; RR, 0.59 [95\% confidence interval (CI), 0.41-0.85]).

ii. In contrast, a single-center study compared povidone-iodine followed by isopropyl alcohol versus chlorhexidine-alcohol versus iodine-alcohol using a sequential implementation design. ${ }^{117}$ General surgical patients who received skin antisepsis with iodine-alcohol had the lowest rates of SSI (3.9 per 100 procedures), compared with 6.4 per 100 procedures for patients who received povidone-iodine followed by alcohol and 7.1 per 100 procedures for patients who received chlorhexidine-alcohol.

iii. In the absence of alcohol, chlorhexidine gluconate may have advantages over povidone-iodine, in- 
cluding longer residual activity and activity in the presence of blood or serum. ${ }^{18,119}$

iv. These disinfectants are not interchangeable. Follow the manufacturers' instructions to ensure correct application.

7. Use impervious plastic wound protectors for gastrointestinal and biliary tract surgery (quality of evidence: I).

a. A wound protector is a plastic sheath that lines a wound and can facilitate retraction of an incision during surgery without the need for additional mechanical retractors.

b. A recent meta-analysis of 6 randomized clinical trials in 1,008 patients reported that use of a plastic wound protectors was associated with a $45 \%$ decrease in SSIs. ${ }^{120}$

$i$. There was a nonsignificant trend toward greater protective effect using a dual-ring protector compared with a single-ring protector.

8. Use a checklist based on the World Health Organization (WHO) checklist to ensure compliance with best practices to improve surgical patient safety (quality of evidence: I).

a. The WHO checklist is a 19-item surgical safety checklist to improve adherence with best practices.

b. A multicenter quasi-experimental study conducted in 8 countries demonstrated that use of the WHO checklist led to lower rates of surgical complications, including SSI and death. ${ }^{121}$

c. These findings have been confirmed in subsequent single-center and multicenter quasi-experimental studies. ${ }^{122,123}$

9. Perform surveillance for SSI (quality of evidence: II).

a. Identify high-risk, high-volume operative procedures to be targeted for SSI surveillance on the basis of a risk assessment of patient populations, operative procedures performed, and available SSI surveillance data.

b. Identify, collect, store, and analyze data needed for the surveillance program. ${ }^{17}$

i. Develop a database for storing, managing, and accessing data collected on SSIs.

ii. Implement a system for collecting data needed to identify SSIs. Data are required from surgical and microbiological databases. Obtain the following data from surgical databases: patient name, medical record number, date, type of procedure, surgeons, anesthesiologists, incision time, wound class, ASA score, closure time, and presence of an SSI. Ideally, these data are supplemented with process data, including prophylactic agent and dose and time(s) of administration of prophylactic agent. For patients diagnosed with an SSI, necessary microbiological data include type of SSI, infecting organism and antimicrobial susceptibilities, and date of infection. More detailed surgical and patient information may be useful for some procedures, including use of general anesthesia, emergency or trauma-related surgery, body mass index, and diagnosis of diabetes.

iii. Prepare periodic SSI reports (time frame will depend on hospital needs and volume of targeted procedures).

iv. Collect denominator data on all patients undergoing targeted procedures in order to calculate SSI rates for each type of procedure. ${ }^{67}$

v. Identify trends (eg, in SSI rates and pathogens causing SSIs).

c. Use updated CDC NHSN definitions for SSI. ${ }^{26}$

d. Perform indirect surveillance for targeted procedures. ${ }^{30,31,124,125}$

e. Perform postoperative surveillance for 30 days; extend the postoperative surveillance period to 90 days for certain procedure categories. ${ }^{26}$

$i$. Procedures that require 90 -day surveillance are determined by specific procedure codes.

f. Surveillance should be performed on patients readmitted to the hospital.

$i$. If an SSI is diagnosed at your institution but the surgical procedure was performed elsewhere, notify the hospital where the original procedure was performed.

g. Develop a system for routine review and interpretation of SSI rates to detect significant increases or outbreaks and to identify areas where additional resources might be needed to improve SSI rates. ${ }^{125}$ If increased rates are identified, determine the number of potentially preventable infections that occurred, defined as the number of SSIs that occurred during a procedure in which less than $100 \%$ of recommended practices and processes were completed.

10. Increase the efficiency of surveillance through utilization of automated data (quality of evidence: II).

a. Implement a method to electronically transfer microbiology and operative data, including process measures when available, to IPC personnel to facilitate denominator data acquisition and calculation of SSI rates for various procedures.

b. If information technology and infrastructure resources are available, develop automated methods for detection of SSIs utilizing automated data for readmissions, diagnosis and procedure codes, microbiology results, and antimicrobial dispensing. $35,126-129$

c. Implementation of automated surveillance may improve the sensitivity of surveillance.

11. Provide ongoing feedback of SSI rates to surgical and perioperative personnel and leadership (quality of evidence: II).

a. Routinely audit and provide confidential feedback on SSI rates and adherence to process measures to in- 
dividual surgeons, the surgical division and/or department chiefs, and hospital leadership. ${ }^{17,130}$

$i$. For each type of procedure performed, provide risk-adjusted rates of SSI.

ii. Anonymously benchmark procedure-specific riskadjusted rates of SSI among peer surgeons.

12. Measure and provide feedback to providers regarding rates of compliance with process measures (quality of evidence: III). ${ }^{58}$

a. Routinely provide feedback to surgical staff, perioperative personnel, and leadership regarding compliance with targeted process measures.

13. Educate surgeons and perioperative personnel about SSI prevention (quality of evidence: III).

a. Include risk factors, outcomes associated with SSI, local epidemiology (eg, SSI rates by procedure, rate of methicillin-resistant Staphylococcus aureus [MRSA] infection in a facility), and basic prevention measures.

14. Educate patients and their families about SSI prevention as appropriate (quality of evidence: III).

a. Provide instructions and information to patients prior to surgery describing strategies for reducing SSI risk. Specifically provide preprinted materials to patients. ${ }^{131}$

b. Examples of printed materials for patients are available from the following websites:

i. JAMA patient page: wound infections (from the Journal of the American Medical Association; available at http://jama.ama-assn.org/cgi/reprint/294 /16/2122).

ii. SCIP's tips for safer surgery (available at https:// www.premierinc.com/safety/topics/scip /downloads/consumer-tips.pdf).

iii. Frequently asked questions about SSIs (available from SHEA at http://www.shea-online.org/Assets /files/patient\%20guides/NNL_SSI.pdf).

iv. SSI: resources for patients and healthcare providers (available from the CDC at http://www.cdc .gov/hai/ssi/ssi.html).

15. Implement policies and practices aimed at reducing the risk of SSI that align with evidence-based standards (eg, CDC, Association for periOperative Registered Nurses, and professional organization guidelines; quality of evidence: II)..$^{17,58,132}$

a. The pathogenesis and likelihood of developing an SSI involves a complex relationship among the following:

i. Microbial characteristics (eg, degree of contamination, virulence of pathogen);

ii. Patient characteristics (eg, immune status, comorbid conditions); and

iii. Surgical characteristics (eg, type of procedure, introduction of foreign material, amount of damage to tissues)..$^{133}$

b. Risk factors for SSI can be separated into intrinsic patient-related characteristics and extrinsic proce- dure-related characteristics. Implement policies and practices to reducing modifiable risk factors (Table 2 ), including the following:

i. Optimal preparation and disinfection of the operative site and the hands of the surgical team members.

ii. Adherence to hand hygiene, including nonsurgeon members of the operating team. ${ }^{134}$

iii. Reduce unnecessary traffic in operating rooms. ${ }^{135,136}$

iv. Appropriate care and maintenance of operating rooms, including appropriate air handling and optimal cleaning and disinfection of equipment and the environment. ${ }^{17}$

II. Special approaches for preventing SSI

Standard infection control methods of outbreak investigation are recommended for use in locations and/or populations within the hospital with unacceptably high SSI rates despite implementation of the basic SSI prevention strategies listed above.

1. Screen for $S$. aureus and decolonize surgical patients with an antistaphylococcal agent in the preoperative setting for high-risk procedures, including some orthopedic and cardiothoracic procedures (quality of evidence: II).

a. Screening for S. aureus refers to the practice of attempting to identify patients colonized with methicillin-susceptible $S$. aureus (MSSA) and/or MRSA. Decolonization refers to the practice of treating patients with known $S$. aureus colonization with antimicrobial and/or antiseptic agents to eliminate $S$. aureus colonization.

$i$. There is no standardized approach to either screening or decolonizing. Most clinicians attempt to decolonize surgical patients with a combination of chlorhexidine gluconate applied to the skin and nasal mupirocin.

b. A Cochrane review concluded that mupirocin alone may be effective, particularly in certain groups, including orthopedic and cardiothoracic patients. ${ }^{137}$ Several nonrandomized trials corroborate this conclusion. ${ }^{138-140}$

c. Clinical practice guidelines from the American Society of Health-System Pharmacists recommend giving mupirocin intranasally to all patients with documented $S$. aureus colonization for orthopedic procedures, including total joint replacement and hip fracture repair, and cardiac procedures. ${ }^{76}$

d. Some trials demonstrate that preoperative screening for $S$. aureus, coupled with intranasal mupirocin and chlorhexidine bathing is effective in reducing SSI for some patients.

$i$. For example, a randomized, double-blind, placebocontrolled, multicenter trial that evaluated rapid identification of $S$. aureus nasal carriers followed 


\begin{tabular}{ll}
\hline Risk factor & Recommendation \\
\hline of evidence
\end{tabular}

Intrinsic, patient related (preoperative)

Unmodifiable

Age

History of radiation

History of SSTIs

Modifiable

Glucose control

Obesity

Smoking cessation

Immunosuppressive medications

Hypoalbuminemia

Extrinsic, procedure related (perioperative)

Preparation of patient

Hair removal

Preoperative infections

Operative characteristics

Surgical scrub (surgical team members' hands and forearms)

Skin preparation

Antimicrobial prophylaxis

Timing

Blood transfusion

Choice of prophylactic agent

Duration of prophylaxis

Surgeon skill/technique

Appropriate gloving

Asepsis

Operative time

OR characteristics

Ventilation

Traffic

Environmental surfaces

Sterilization of surgical equipment
No formal recommendation. Relationship to increased risk of SSI may be secondary to comorbidities or immunosenescence. ${ }^{216-218}$

No formal recommendation. Prior irradiation at the surgical site increases the risk of SSI, likely due to tissue damage and wound ischemia. ${ }^{219}$

No formal recommendation. History of a prior skin infection may be a marker for inherent differences in host immune function. ${ }^{220}$

Control serum blood glucose levels for all surgical patients, including patients without diabetes. ${ }^{17}$ For patients with diabetes mellitus, reduce glycosylated hemoglobin Alc levels to less than $7 \%$ before surgery, if possible. ${ }^{94}$

Increase dosing of prophylactic antimicrobial agent for morbidly obese patients. $^{76,221}$

Encourage smoking cessation within 30 days of procedure. ${ }^{17,222-226}$

Avoid immune-suppressive medications in perioperative period, if possible.

No formal recommendation. Although a noted risk factor, ${ }^{227}$ do not delay surgery for use of TPN.

Do not remove unless hair will interfere with the operation. ${ }^{17}$ If hair removal is necessary, remove outside the OR by clipping. Do not use razors.

Identify and treat infections (eg, urinary tract infection) remote to the surgical site prior to elective surgery. ${ }^{17}$ Do not routinely treat colonization or contamination.

Use appropriate antiseptic agent to perform preoperative surgical scrub. ${ }^{17,228}$ For most products, scrub the hands and forearms for $2-5$ minutes.

Wash and clean skin around incision site. Use a dual agent skin preparation containing alcohol, unless contraindications exist. ${ }^{17}$

Administer only when indicated. ${ }^{17}$

Administer within 1 hour of incision to maximize tissue concentration ${ }^{76, a}$

Blood transfusions increase the risk of SSI by decreasing macrophage function. Reduce blood loss and need for blood transfusion to the greatest extent possible. ${ }^{229-231}$

Select appropriate agents on the basis of surgical procedure, most common pathogens causing SSIs for a specific procedure, and published recommendations. ${ }^{76}$

Stop agent within 24 hours after the procedure for all procedures. ${ }^{76}$

Handle tissue carefully and eradicate dead space..$^{7}$

All members of the operative team should double glove and change gloves when perforation is noted. ${ }^{208}$

Adhere to standard principles of OR asepsis. ${ }^{17}$

No formal recommendation in most recent guidelines. Minimize as much as possible without sacrificing surgical technique and aseptic practice.

Follow American Institute of Architects' recommendations for proper air handling in the OR. ${ }^{17,232}$

Minimize OR traffic..$^{17,135,136}$

Use an EPA-approved hospital disinfectant to clean visibly soiled or contaminated surfaces and equipment. ${ }^{17}$

Sterilize all surgical equipment according to published guidelines. ${ }^{233}$ Minimize the use of immediate-use steam sterilization. ${ }^{17}$
NA

NA

NA

I

NotE. EPA, Environmental Protection Agency; NA, not applicable; OR, operating room; SSTI, skin and soft-tissue infection; TPN, total parenteral nutrition.

"Vancomycin and fluoroquinolones can be given 2 hours prior to incision. 
by decolonization was associated with a greater than 2 -fold reduction in the risk for postoperative infection due to $S$. aureus and an almost 5-fold reduction in risk for deep incisional SSI due to $S$. aureus. ${ }^{141}$

(a) This study was performed in a setting with high baseline rates of SSI and in the absence of MRSA.

e. In contrast, other trials have failed to demonstrate a benefit.

i. A prospective, interventional cohort study with a crossover design involving 21,000 patients concluded that universal, rapid screening for MRSA at admission coupled with decolonization of carriers did not reduce the rate of SSI due to MRSA..$^{142}$

ii. A double-blind randomized controlled trial involving more than 4,000 patients showed that intranasal application of mupirocin, which was not coupled with chlorhexidine bathing, did not significantly reduce the $S$. aureus SSI rate. ${ }^{143}$

(a) In a secondary analysis of these data, the use of intranasal mupirocin was associated with an overall decreased rate of nosocomial $S$. aureus infections among the $S$. aureus carriers.

f. A recently published meta-analysis of 17 studies concluded that decolonization strategies prevent grampositive SSIs, S. aureus SSIs, and MRSA SSIs, although there was significant heterogeneity among the trials. ${ }^{144}$

g. Factors that impact the decision to implement screening for $S$. aureus and decolonization include adherence to basic SSI prevention strategies, baseline rate of SSI due to $S$. aureus, individual patient risk factors for acquiring SSI due to $S$. aureus, availability of resources to implement the protocol, and ability to follow-up on protocol parameters (eg, laboratory results) and adherence.

h. Routine preoperative decolonization with mupirocin without screening is not currently recommended. i. Mupirocin resistance has been documented. ${ }^{145}$

2. Perform antiseptic wound lavage (quality of evidence: II).

a. Wound lavage is a common practice, although the solution used for lavage differs among surgeons. ${ }^{146}$

b. Several groups have evaluated whether dilute povidone-iodine lavage of the surgical wound can decrease the risk of SSI. A meta-analysis published in 2010 evaluated 24 randomized controlled trials and concluded that lavage with dilute povidone-iodine decreased the risk of SSI compared with nonantiseptic lavage (RR, 0.64 [95\% CI, 0.51-0.82])..$^{147}$

3. Perform an SSI risk assessment (quality of evidence: III).

a. Convene a multidisciplinary team (eg, surgical leadership, hospital administration, quality management services, and infection control) to identify gaps, improve performance, measure compliance, assess impact of interventions, and provide feedback. ${ }^{148}$ b. Determine baseline SSI rates by surgical specialty, procedure, and/or surgeon to better target your evaluation and interventions.

4. Observe and review operating room personnel and the environment of care in the operating room (quality of evidence: III).

a. Perform direct observation audits of operating room personnel to assess operating room processes and practices to identify infection control lapses, including but not limited to adherence to process measures (antimicrobial prophylaxis choice, timing and duration protocols, hair removal, etc), surgical hand antisepsis, patient skin preparation, operative technique, surgical attire (wearing and/or laundering outside the operating room), and level of operating room traffic. ${ }^{149-153}$ Perform remediation when breaches of standards are identified.

i. Operating room personnel should include surgeons, surgical technologists, anesthesiologists, circulating nurses, residents, medical students, trainees, and device manufacturer representatives. ${ }^{149}$

b. Perform direct-observation audits of environmental cleaning practices in the operating room, instrument processing (sterilization), and storage facilities.

$i$. Review instrument processing and flash sterilization logs.

ii. Review maintenance records for operating room heating, ventilation, and air conditioning system, including results of temperature and relative humidity testing, and test for maintenance of positive air pressure in the operating room(s).

c. Provide feedback and review infection control measures with operating room and environmental personnel.

5. Observe and review practices in the postanesthesia care unit, surgical intensive care unit, and/or surgical ward (quality of evidence: II).

a. Perform direct observation audits of hand hygiene practices among all personnel with direct patient contact. $^{151}$

b. Evaluate wound care practices. ${ }^{154}$

c. Perform direct observation audits of environmental cleaning practices.

d. Provide feedback and review infection control measures with staff in these postoperative care settings.

III. Approaches that should not be considered a routine part of SSI prevention

1. Do not routinely use vancomycin for antimicrobial prophylaxis (quality of evidence: II). ${ }^{75,76,155}$

a. Vancomycin should not routinely be used for antimicrobial prophylaxis, but it can be an appropriate agent for specific scenarios. Reserve vancomycin for specific clinical circumstances, such as a proven outbreak of SSI due to MRSA; high endemic rates of SSI due to MRSA; targeted high-risk patients who are at 
increased risk for SSI due to MRSA (including cardiothoracic surgical patients and elderly patients with diabetes); and high-risk surgical procedures in which an implant is placed. ${ }^{156}$

i. No definitions for high endemic rates of SSI due to MRSA have been established. ${ }^{157}$

ii. Studies of the efficacy of vancomycin prophylaxis were published prior to the emergence of community-acquired MRSA.

b. Two meta-analyses of studies comparing glycopeptides to $\beta$-lactam antimicrobial prophylaxis concluded that there was no difference in rates of SSI between the 2 antimicrobial prophylaxis regimens. ${ }^{144,158}$

c. A meta-analysis of 6 studies concluded that prophylaxis with a glycopeptide and a second agent was protective against SSI due to gram-positive organisms compared with prophylaxis with a $\beta$-lactam alone.$^{144}$ Of note, the 2 randomized controlled trials included in the metaanalysis combined a glycopeptide with non- $\beta$-lactam antibiotic(s). Thus, no study has prospectively analyzed the effect of providing both glycopeptides and $\beta$-lactam antimicrobials for preoperative antimicrobial prophylaxis. As vancomycin does not have activity against gram-negative pathogens and appears to have less activity against MSSA than $\beta$-lactam agents, many experts recommend adding vancomycin to standard antimicrobial prophylaxis for the specific clinical circumstances described above. ${ }^{76,157-159}$

2. Do not routinely delay surgery to provide parenteral nutrition (quality of evidence: I).

a. Preoperative administration of total parenteral nutrition has not been shown to reduce the risk of SSI in prospective randomized controlled trials and may increase the risk of SSI. ${ }^{160,161}$

b. Individual trials comparing enteral and parenteral perioperative nutrition and "immunomodulating" diets containing arginine and/or glutamine with "standard" control diets tend to have very small numbers and fail to show significant differences. Two recent meta-analyses, however, demonstrate reduction in postoperative infectious complication in patients receiving enteral diets containing glutamine and/or arginine administered either before or after the surgical procedure. ${ }^{162,163}$

3. Do not routinely use antiseptic-impregnated sutures as a strategy to prevent SSIs (quality of evidence: II).

a. Human volunteer studies involving foreign bodies have demonstrated that the presence of surgical sutures decreases the inoculum required to cause an SSI from $10^{6}$ to $10^{2}$ organisms. ${ }^{164}$

b. Some trials have shown that surgical wound closure with triclosan-coated polygactin 910 antimicrobial sutures may decrease the risk of SSI compared with standard sutures. For example, a recent randomized controlled trial of 410 colorectal surgeries concluded that the rate of SSI decreased more than $50 \%(9.3 \%$ in the control group vs $4.3 \%$ among cases; $P=.05$ ). ${ }^{165}$

c. In contrast, a recent systematic review and meta-analysis evaluated 7 randomized clinical trials and concluded that neither rates of SSI (odds ratio [OR], 0.77 [95\% CI, 0.4-1.51]; $P=.45$ ) nor rates of wound dehiscence (OR, 1.07 [95\% CI, 0.21-5.43]; $P=.93$ ) were statistically different compared with controls. ${ }^{166}$ In addition, one small study raised concern about higher rates of wound dehiscence while using these sutures. ${ }^{167}$

d. The impact of routine use of antiseptic-impregnated sutures on development of resistance to antiseptics is unknown.

4. Do not routinely use antiseptic drapes as a strategy to prevent SSIs (quality of evidence: I).

a. An incise drape is an adhesive film that covers the surgical incision site to minimize bacterial wound contamination due to endogenous flora. These drapes can be impregnated with antiseptic chemicals, such as iodophors.

b. A 2007 Cochrane review of 5 trials concluded that nonantiseptic incise drapes were associated with a higher risk of SSI compared with no incise drape (RR, 1.23 [95\% CI, 1.02-1.48]), ${ }^{168}$ although this association may have been caused by one specific study. ${ }^{169}$ Two trials (abdominal and cardiac surgical patients) compared iodophor-impregnated drapes to no drapes. ${ }^{170,171}$ While wound contamination was decreased in one trial, ${ }^{170}$ neither trial demonstrated that iodophor-impregnated drapes decreased the rate of SSI. A nonrandomized retrospective study similarly concluded that impregnated drapes do not prevent SSIs after hernia repair. ${ }^{172}$

IV. Unresolved issues

1. Preoperative bathing with chlorhexidine-containing products.

a. Preoperative bathing with agents such as chlorhexidine has been shown to reduce bacterial colonization of the skin. ${ }^{173}$ Several studies have examined the utility of preoperative showers, but none has definitively proven that they decrease SSI risk. A Cochrane review evaluated the evidence for preoperative bathing or showering with antiseptics for SSI prevention. ${ }^{174}$ Six randomized controlled trials evaluating the use of $4 \%$ chlorhexidine gluconate were included in the analysis, with no clear evidence of benefit noted. It should be noted that several of these studies had methodological limitations and were conducted several years ago. Thus, the role of preoperative bathing in SSI prevention is still uncertain.

$i$. To gain the maximum antiseptic effect of chlorhexidine, adequate levels of CHG must be achieved and maintained on the skin. Typically, adequate levels are achieved by allowing CHG to dry com- 
pletely. New strategies for preoperative bathing with chlorhexidine, such as preimpregnated cloths, have shown promise, ${ }^{175,176}$ but data are currently insufficient to support this approach.

2. Preoperative intranasal and pharyngeal chlorhexidine treatment for patients undergoing cardiothoracic procedures.

a. Although data from a randomized controlled trial exist to support the use of chlorhexidine nasal cream combined with $0.12 \%$ chlorhexidine gluconate mouthwash, ${ }^{177}$ chlorhexidine nasal cream is neither approved by the Food and Drug Administration (FDA) nor commercially available in the United States.

3. Use of gentamicin-collagen sponges.

a. Gentamicin-collagen sponges have been evaluated as a way to decrease SSI among colorectal and cardiac surgical patients.

i. Colorectal surgical patients. Several single-center randomized trials have demonstrated that gentamicin-collagen sponges decrease the risk of SSI following colorectal procedures. ${ }^{178-180}$ The rate of SSI was higher with the sponge, however, in a recent large, multicenter randomized clinical trial. ${ }^{181}$

ii. Cardiothoracic surgical patients. Four randomized controlled trials have evaluated the use of gentamicin-collagen sponges in cardiothoracic surgery. Three of these trials demonstrated a decrease in SSIs, ${ }^{182-184}$ and one showed no difference. ${ }^{185} \mathrm{~A}$ recent meta-analysis combining these trials concluded that the risk of deep sternal wound infection was significantly lower in patients who received a gentamicin-collagen sponge than in patients who did not (RR, 0.62 [95\% CI, 0.39-0.97]) despite significant heterogeneity among the trials. ${ }^{186}$

b. Gentamicin-collagen sponges are not currently approved by the FDA for use in the United States.

4. Use of bundles to ensure compliance with best practices.

a. Bundles have been promoted as methods to improve adherence to best practices.

b. Although generally favorable, the use of bundles for the prevention of SSI has led to mixed results, depending on which components are included..$^{59,187,188}$

c. Thus, there is no consensus on the components of an effective bundle to prevent SSIs.

\section{SECTION 5: PERFORMANCE MEASURES}

I. Internal reporting

These performance measures are intended to support internal hospital quality improvement efforts and do not necessarily address external reporting needs. The process and outcome measures suggested here are derived from published guidelines, other relevant literature, and the opinion of the authors. Report process and outcome measures to senior hospital leadership, nursing leadership, and clinicians who care for patients at risk for SSI.

A. Process measures

1. Compliance with antimicrobial prophylaxis guidelines.

a. Measure the percentage of procedures in which antimicrobial prophylaxis was appropriately provided. Appropriateness includes (1) correct type of agent, (2) start of administration of the agent within 1 hour of incision ( 2 hours allowed for vancomycin and fluoroquinolones), and (3) discontinuation of the agent within 24 hours after surgery.

$i$. Numerator: number of patients who appropriately received antimicrobial prophylaxis.

ii. Denominator: total number of selected operations performed.

iii. Multiply by 100 so that the measure is expressed as a percentage.

2. Compliance with hair removal guidelines.

a. Measure the percentage of procedures for which hair removal is appropriately performed (ie, clipping, use of a depilatory or no hair removal is performed rather than use of razor).

$i$. Numerator: number of patients with appropriate perioperative hair removal.

ii. Denominator: total number of selected operations performed.

iii. Multiply by 100 so that the measure is expressed as a percentage.

3. Compliance with perioperative glucose control guidelines.

a. Measure the percentage of procedures for which serum glucose is $180 \mathrm{mg} / \mathrm{dL}$ or lower within 1824 hours after anesthesia end time for all cardiac surgery patients. ${ }^{60,61,100}$

$i$. Numerator: number of patients with appropriately maintained serum glucose $(180 \mathrm{mg} / \mathrm{dL}$ or lower) in the time frame of 18-24 hours after anesthesia end time following cardiac surgery.

ii. Denominator: total number of cardiac procedures performed.

iii. Multiply by 100 so that the measure is expressed as a percentage.

B. Outcome measures

1. SSI rate

a. Use NHSN definitions and risk adjustment methods for SSI (available at http://www.cdc.gov/nhsn /acute-care-hospital/ssi/index.html).

i. Numerator: number of patients with an SSI following selected operations.

ii. Denominator: total number of selected operations performed.

iii. Multiply by 100 so that the measure is expressed as the number of SSIs per 100 procedures.

iv. Rates of SSI can be risk adjusted using one of 2 methods: stratification using the NHSN risk 
index ${ }^{133}$ or calculation of the standardized infection ratio (SIR). ${ }^{189}$ NHSN now promotes the use of SIR over the NHSN risk index for improved risk adjustment potential, ${ }^{190}$ and SIR is preferentially used for the national public reporting outcome measure within NHSN.

(a) The NHSN risk index is an operation- and patient-specific prospectively applied risk score that predicts SSIs. ${ }^{191}$ This risk index includes 3 predictors of increased risk of SSI: (1) estimators of wound microbial contamination, (2) duration of operation, and (3) markers for host susceptibility. ${ }^{42}$

(b) SIR is the ratio of the observed number of SSIs $(O)$ that occurred compared with the expected number for a surgeon performing a specific type of procedure $(E$; eg, SIR $=$ $O / E){ }^{189}$ The expected number of SSIs can be obtained by multiplying the number of operations done by the surgeon in each procedure risk category by the NHSN rate for the same procedure risk category and dividing by 100 . Values that exceed 1.0 indicate that more SSIs occurred than expected. Importantly, SIR can only be calculated if the number of expected HAIs is $\geq 1$. Thus, this approach may be more difficult for small surgical programs or if few procedures are performed for any one procedure type. ${ }^{192}$

(c) Risk adjustment using logistic regression and the SIR method generally provides better riskadjustment than the basic risk index. ${ }^{190,193}$

\section{External reporting}

There are many challenges in providing useful information to consumers and other stakeholders while preventing unintended adverse consequences of public reporting of HAIs. ${ }^{194}$ Recommendations and requirements for public reporting of HAIs have been provided by HICPAC, ${ }^{195}$ the Healthcare-Associated Infection Working Group of the Joint Public Policy Committee, ${ }^{54}$ the National Quality Forum, ${ }^{55}$ and CMS. ${ }^{196}$ The following is an example of an external performance measure that is currently required by some healthcare stakeholders and regulators.

A. Process measures

1. Compliance with CMS antimicrobial prophylaxis guidelines (see the section above on internal reporting in "Section 5: Performance Measures").

a. Measure the percentage of procedures in which antimicrobial prophylaxis was appropriately provided. Appropriateness includes correct type of agent, administration of the agent within 1 hour of incision ( 2 hours are allowed for vancomycin and fluoroquinolones), and discontinuation of the agent within 24 hours after surgery ( 48 hours for cardiothoracic procedures). ${ }^{197}$

2. Compliance with the CMS guideline for control of postoperative blood glucose in cardiac surgery patients.

a. Measure the percentage of procedures in which postoperative blood glucose was appropriately controlled in cardiac surgery patients.

B. Federal and state requirements

1. Federal requirements

a. The CMS published a final rule in the Federal Register on August 18, 2011, that includes SSI reporting via the CDC's NHSN in the CMS Hospital IQR program requirements for $2012 .{ }^{196}$ More specifically, the rule announced a reporting requirement for SSI data for inpatient abdominal hysterectomy and inpatient colon procedures beginning with surgical procedures performed on January 1, 2012. ${ }^{198}$

b. The requirements for SSI reporting to NHSN for the IQR program do not preempt or supersede state mandates for SSI reporting to NHSN (ie, hospitals in states with an SSI reporting mandate must abide by their state's requirements, even if they are more extensive than the requirements for this CMS program). NHSN users reporting SSI data to the system must adhere to the definitions and reporting requirements for SSIs as specified in the NHSN Patient Safety Component Protocol Manual. ${ }^{198}$ For more information, see http://www.cdc.gov/nhsn /acute-care-hospital/ssi/index.html.

2. State requirements and collaboratives

a. State requirements. Hospitals in states that have mandatory SSI reporting requirements must collect and report the data required by the state. For information on state requirements, check with your state or local health department.

b. State collaboratives. Currently 27 states have implemented voluntary SSI collaboratives. For more information on state collaboratives for SSI, see http://www.cdc.gov/hai/stateplans/states-w-SSI -collaborative.html.

\section{External quality initiatives}

a. Several external quality initiatives focused on SSI prevention are ongoing. The benefits in participation in these external quality initiatives is unknown but may include improvement in the culture of safety and patient outcomes, including decreased rates of SSI. For additional information, see the following:

i. http://www.ahrq.gov/qual/haifyll.htm\#projects

ii. http://www.ihi.org/Engage/Initiatives/Completed /ProjectJOINTS/Pages/default.aspx 
TABLE 3. Fundamental Elements of Accountability for Healthcare-Associated Infection Prevention

Senior management is responsible for ensuring that the healthcare system supports an infection prevention and control (IPC) program that effectively prevents healthcare-associated infections (HAIs) and the transmission of epidemiologically important pathogens

Senior management is accountable for ensuring that an adequate number of trained personnel are assigned to the IPC program and adequate staffing of other departments that play a key role in HAI prevention (eg, environmental services)

Senior management is accountable for ensuring that healthcare personnel, including licensed and nonlicensed personnel, are adequately trained and competent to perform their job responsibilities

Direct healthcare providers (such as physicians, nurses, aides, and therapists) and ancillary personnel (such as environmental service and equipment processing personnel) are responsible for ensuring that appropriate IPC practices are used at all times (including hand hygiene, standard and isolation precautions, and cleaning and disinfection of equipment and the environment)

Senior and unit leaders are responsible for holding personnel accountable for their actions

IPC leadership is responsible for ensuring that an active program to identify HAIs is implemented, that HAI data are analyzed and regularly provided to those who can use the information to improve the quality of care (eg, unit staff, clinicians, and hospital administrators), and that evidence-based practices are incorporated into the program

Senior and unit leaders are accountable for ensuring that appropriate training and educational programs to prevent HAIs are developed and provided to personnel, patients, and families

Personnel from the IPC program, the laboratory, and information technology departments are responsible for ensuring that systems are in place to support the surveillance program

\section{SECTION 6: EXAMPLES OF}

\section{IMPLEMENTATION STRATEGIES}

Accountability is an essential principle for preventing HAIs. It provides the necessary translational link between science and implementation. Without clear accountability, scientifically based implementation strategies will be used in an inconsistent and fragmented way, decreasing their effectiveness in preventing HAIs. Accountability begins with the chief executive officer and other senior leaders who provide the imperative for HAI prevention, thereby making HAI prevention an organizational priority. Senior leadership is accountable for providing adequate resources needed for effective implementation of an HAI prevention program. These resources include necessary personnel (clinical and nonclinical), education, and equipment (Table 3 ).

The following information identifies implementation strategies that can be used as part of a program to prevent and reduce the risk for SSI. The implementation strategies are organized under 4 concepts: engage, educate, execute, and evaluate. $^{.99}$

\section{Engage}

In the engagement phase, there needs to be clear and effective communication pertaining to the reasons why the SSI implementation strategies are important for patient care. Engagement of senior leadership, physician champions, infection preventionists, and multidisciplinary teams are examples of strategies necessary for initial implementation of a program to reduce SSIs. The following implementation strategies are described in the literature as being essential for the engagement process.

A. Obtaining support for SSI reduction from senior leadership. Senior leadership support is an important factor contributing to SSI rate decreases. Senior leadership is also critical for sustaining improvements over time. Senior leadership can include but is not limited to the hospital's board, president, chief operating officer, chief medical officer, and chief nursing officer. ${ }^{148,200-203}$

B. Obtaining highly engaged physicians as champions. Medical and surgical staff engagement is critical for SSI prevention activities and to champion SSI prevention throughout the hospital. Examples include a physician leading an SSI prevention multidisciplinary team and a physician champion who provides education on strategies to reduce SSIs to other physicians and staff. ${ }^{202,203}$

C. Use of multidisciplinary teams. Numerous studies and literature address the effectiveness of multidisciplinary teams to plan, develop, implement, and evaluate efforts to reduce SSIs. The key components of the team include preoperative, intraoperative, and postoperative management of the patient. Teams should include nursing, pharmacy, and physician champions. ${ }^{148,200,204-207}$

D. Adopting evidence-based practices and guidelines. Several studies in the literature focus on the need for hospitals to adopt evidence-based practices and guidelines in an effort to decrease the risk of SSIs. The literature stresses that, although evidence-based interventions can reduce the number of SSIs and improve patient outcomes, implementation of these practices nationally occurs less frequently than is desirable. . $^{10,148,203,208-210}$

E. Focus on a culture of safety. The literature supports the need for a culture of safety to successfully implement a program focusing on reducing SSIs. A culture of safety focuses on teamwork, technical processes, and promoting accountability for preventing SSIs throughout the continuum of care..$^{136,200,202}$

\section{Educate}

Education pertaining to practices to prevent SSIs is es- 
sential for senior leadership, physicians, nurses, and patients and families. The following implementation strategies describe the types of education that can impact SSI rates and who should be the focus of educational efforts.

A. Aligned and coordinated SSI education for licensed independent practitioners and staff. Multidisciplinary education for licensed independent practitioners (physicians and midlevel practitioners) and other practitioner staff (registered nurses) must be aligned and coordinated. The content of the education focuses on the continuum of the patient's care and execution of evidence-based practices to prevent SSIs. ${ }^{202,203}$

B. One-to-one education of the surgeon when an SSI issue is identified. Provide one-to-one education when surgeons have elevated SSI rates and/or when appropriate preventive processes are not being adhered to. This education may be conducted by another surgeon, infection preventionist, quality office, or other qualified individuals. The education should be nonconfrontational with an emphasis on understanding variation in practice rather than judgment. If lack of adherence to evidence-based practices is identified, then an action plan must be developed. ${ }^{203}$

C. Education for senior leadership that describes the value and benefits of SSI reduction. Provide education to executive leadership regarding the value of reducing SSIs, including patient and fiscal outcomes. ${ }^{131}$

D. Education for the surgical team on safety science. Provide education to licensed independent practitioners and staff involved in the care of surgical patients on the science of safety, including the principles of safe system design. ${ }^{200}$

E. Specific SSI education for patients and families. Patient education for reducing SSIs is a major priority for any hospital focused on preventing SSIs. Education strategies such as presurgical classes, television education, and one-to-one education with the patient and family have been used successfully. Educational materials should be provided in multiple languages on the basis of the population served. ${ }^{131,202,203}$

III. Execute

In the execution phase, the focus is on implementation strategies to reduce barriers and improve adherence with evidence-based practices and reduce the risk of SSIs, including $(a)$ standardization of care processes, $(b)$ creating redundancy or independent checks, and $(c)$ learning from defects when an SSI occurs. As noted above, no consensus exists on the components of an effective bundle to prevent SSIs. Thus, individual hospitals must identify local deficits and create their own bundle.

A. Use a quality improvement methodology. Use of quality improvement methodology for designing and implementing a program leads to reduced rates of SSIs. Quality improvement methodologies include Lean Six Sigma, the Comprehensive Unit-Based Safety Program, and the Plan-Do-Check-Act model. Various performance improvement (PI) tools have been used, including dashboards, scorecards, and histograms, to display data. ${ }^{199,200,203,207,211}$

B. Differentiate between adult and pediatric populations. Pediatric-focused evidence-based practices for reducing SSIs are lacking. Clinical interventions designed for the adult population cannot necessarily be transferred to the pediatric population. Hospital and pediatric surgeons must determine whether adult evidence-based interventions can be safely used with the pediatric population. ${ }^{203}$

C. Use of information technologies (IT). IT innovations can be used to simplify and standardize clinical documentation. IT and the electronic medical record can also be used for electronic surveillance, electronic prompts, automatic stops for prophylactic antibiotic orders, and education. Education can be delivered to patients, families, and healthcare workers through different media, including the Internet and television. . $^{148,202,203,212}$

D. Participation in a collaborative. Numerous studies have reported that participation in a collaborative can help reduce SSI rates in participating organizations. Collaboratives provide a mechanism for organizations to

1. Utilize valid data, such as with the American College of Surgeons National Surgical Quality Improvement Program; ${ }^{213}$

2. Identify increased morbidity and mortality through comparisons to peer hospitals on a national basis; ${ }^{213}$ and

3. Learn through the collaboration process. $^{161,202,203,205,207,209,213,214}$

E. Use of preoperative/postoperative order sets. Standardized order sets can be developed on the basis of evidencebased practices. The order sets should be approved by the medical staff and updated when the evidence-based practices change. The development of order sets is a labor-intensive process necessitating skills and expertise of several disciplines, including surgery, anesthesia, nursing, and pharmacy. All relevant disciplines should be educated in the use of the order sets. ${ }^{148,202,203}$

F. Acting on identified SSI issues. When issues suspected of increasing the risk of SSI are identified, the hospital should take action to resolve the identified issues. Several hospitals conduct root-cause analyses with a multidisciplinary team to identify the cause of the issues and any lack of adherence in the evidence-based practices. ${ }^{149,202-204}$

G. Establish a protocol for preoperative testing. Establish a protocol for procedure-specific preoperative testing to detect medical conditions that increase the risk of SSI. The protocol should focus on nutritional counseling if indicated, smoking cessation if indicated, preadmission infections, and reconciling medications with adjustments prior to surgery if indicated. ${ }^{202}$ If high-risk pa- 
tients are identified through screening, alerts should be added to electronic medical records to ensure that all members of the perioperative team are aware of the high-risk condition(s).

IV. Evaluate

In the evaluation phase, the focus is on the use of measurement and evaluation tools to determine the effectiveness of implementation strategies in the prevention of SSIs.

A. Use of performance improvement tools. Various PI tools can be used. PI tools include dashboards, scorecards, or histograms to display data. Additional PI tools can include root-cause analysis and failure modes and effects analysis. ${ }^{148,202,203}$

B. Direct observation of evidence-based practices. As part of a hospital's SSI improvement activities, trained observers (eg, infection preventionists, educators, nurses, and physicians) should observe surgery to assure that evidence-based practices have been implemented in the operating room. Direct observation can also be conducted for hand hygiene and surgical hand antisepsis technique. This activity is used to educate and reinforce evidence-based practices with the operating room practitioners. $136,149,203,214$

C. Longitudinal evaluation of SSI rates and compliance rates. Track the success of the SSI reduction program by evaluating SSI rates over time (ie, before, during, and after the program). If specific practices or processes are identified for improvement, evaluate the compliance with evidence-based practices related to these practices and processes. Feed these data evaluations back to frontline staff.

\section{ACKNOWLEDGMENTS}

Disclaimer. S.I.B.-T.-The findings and conclusions in this report are those of the authors and do not necessarily represent the official position of the Centers for Disease Control and Prevention.

Potential conflicts of interest. E.P.D. reports serving as an advisor/consultant for Merck, Baxter, Ortho-McNeil, Targanta, Rib-X, Affinium, 3M, Schering-Plough, Astellas, CareFusion, Durata, Pfizer, and Applied Medical and receiving grant support from Tetraphase. L.G. reports receiving honoraria from Premier, CareFusion, and Infection Control Today. K.S.K. reports receiving grant support and serving as an advisor/consultant for Sage Products. D.J.A., K.P., D.W.B., S.I.B.-T., A.-C.N., L.L.M., L.S., and D.S.Y. report no relevant conflicts of interest.

Address correspondence to Deverick J. Anderson, MD, MPH, Division of Infectious Diseases, Box 102359, Duke University Medical Center, Durham, NC 27710 (deverick.anderson@duke.edu).

\section{REFERENCES}

1. Anderson DJ, Kaye KS, Classen D, et al. Strategies to prevent surgical site infections in acute care hospitals. Infect Control Hosp Epidemiol 2008;29(suppl 1):S51-S61.

2. Yokoe DS, Anderson DJ, Berenholtz SM, et al. Introduction to
"A Compendium of Strategies to Prevent Healthcare-Associated Infections in Acute Care Hospitals: 2014 Updates." Infect Control Hosp Epidemiol 2014;35(5):455-459.

3. Cruse P. Wound infection surveillance. Rev Infect Dis 1981; 3(4):734-737.

4. Graves EJ. National Hospital Discharge Survey: Annual Summary, 1987. Series 13, no. 99. Hyattsville, MD: National Center for Health Statistics, 1989.

5. Agency for Healthcare Research and Quality. Healthcare Cost and Utilization Project-statistics on hospital stays. 2013. http://hcupnet.ahrq.gov/. Accessed February 15, 2013.

6. Scott RD. The Direct Medical Costs of Healthcare-Associated Infections in U.S. Hospitals and the Benefits of Prevention. Atlanta: Centers for Disease Control and Prevention, 2009. http://www.cdc.gov/hai/pdfs/hai/scott_costpaper.pdf. Accessed December 14, 2013.

7. Anderson DJ, Pyatt DG, Weber DJ, Rutala WA. Statewide costs of health care-associated infections: estimates for acute care hospitals in North Carolina. Am J Infect Control 2013;41(9): 764-768.

8. Lewis SS, Moehring RW, Chen LF, Sexton DJ, Anderson DJ. Assessing the relative burden of hospital-acquired infections in a network of community hospitals. Infect Control Hosp Epidemiol 2013;34(11):1229-1230.

9. Zimlichman E, Henderson D, Tamir O, et al. Health careassociated infections: a meta-analysis of costs and financial impact on the us health care system. JAMA Intern Med 2013; 173(22):2039-2046.

10. Meeks DW, Lally KP, Carrick MM, et al. Compliance with guidelines to prevent surgical site infections: as simple as 1-2-3? Am J Surg 2011;201(1):76-83.

11. Umscheid CA, Mitchell MD, Doshi JA, Agarwal R, Williams $\mathrm{K}$, Brennan PJ. Estimating the proportion of healthcare-associated infections that are reasonably preventable and the related mortality and costs. Infect Control Hosp Epidemiol 2011;32(2): 101-114.

12. Klevens RM, Edwards JR, Richards CL Jr, et al. Estimating health care-associated infections and deaths in U.S. hospitals, 2002. Public Health Rep 2007;122(2):160-166.

13. Cruse PJ, Foord R. The epidemiology of wound infection: a 10 -year prospective study of 62,939 wounds. Surg Clin North Am 1980;60(1):27-40.

14. Anderson DJ, Kaye KS, Chen LF, et al. Clinical and financial outcomes due to methicillin resistant Staphylococcus aureus surgical site infection: a multi-center matched outcomes study. PloS ONE 2009;4(12):e8305.

15. Engemann JJ, Carmeli Y, Cosgrove SE, et al. Adverse clinical and economic outcomes attributable to methicillin resistance among patients with Staphylococcus aureus surgical site infection. Clin Infect Dis 2003;36(5):592-598.

16. Kirkland KB, Briggs JP, Trivette SL, Wilkinson WE, Sexton DJ. The impact of surgical-site infections in the 1990s: attributable mortality, excess length of hospitalization, and extra costs. Infect Control Hosp Epidemiol 1999;20(11):725-730.

17. Mangram AJ, Horan TC, Pearson ML, Silver LC, Jarvis WR; Hospital Infection Control Practices Advisory Committee. Guideline for prevention of surgical site infection, 1999. Infect Control Hosp Epidemiol 1999;20(4):250-278.

18. Apisarnthanarak A, Jones M, Waterman BM, Carroll CM, Bernardi R, Fraser VJ. Risk factors for spinal surgical-site infections 
in a community hospital: a case-control study. Infect Control Hosp Epidemiol 2003;24(1):31-36.

19. Boyce JM, Potter-Bynoe G, Dziobek L. Hospital reimbursement patterns among patients with surgical wound infections following open heart surgery. Infect Control Hosp Epidemiol 1990; 11(2):89-93.

20. Coello R, Glenister H, Fereres J, et al. The cost of infection in surgical patients: a case-control study. J Hosp Infect 1993;25(4): 239-250.

21. Hollenbeak CS, Murphy DM, Koenig S, Woodward RS, Dunagan WC, Fraser VJ. The clinical and economic impact of deep chest surgical site infections following coronary artery bypass graft surgery. Chest 2000;118(2):397-402.

22. VandenBergh MF, Kluytmans JA, van Hout BA, et al. Costeffectiveness of perioperative mupirocin nasal ointment in cardiothoracic surgery. Infect Control Hosp Epidemiol 1996;17(12): 786-792.

23. Vegas AA, Jodra VM, Garcia ML. Nosocomial infection in surgery wards: a controlled study of increased duration of hospital stays and direct cost of hospitalization. Eur J Epidemiol 1993; 9(5):504-510.

24. Whitehouse JD, Friedman ND, Kirkland KB, Richardson WJ, Sexton DJ. The impact of surgical-site infections following orthopedic surgery at a community hospital and a university hospital: adverse quality of life, excess length of stay, and extra cost. Infect Control Hosp Epidemiol 2002;23(4):183-189.

25. Bozic KJ, Katz P, Cisternas M, Ono L, Ries MD, Showstack J. Hospital resource utilization for primary and revision total hip arthroplasty. J Bone Joint Surg Am 2005;87(3):570-576.

26. National Healthcare Safety Network. Surgical Site Infection (SSI) Event. Atlanta: Centers for Disease Control and Prevention, 2013. http://www.cdc.gov/nhsn/PDFs/pscManual/9pscSSIcurrent.pdf. Accessed May 1, 2013.

27. Condon RE, Schulte WJ, Malangoni MA, Anderson-Teschendorf MJ. Effectiveness of a surgical wound surveillance program. Arch Surg 1983;118(3):303-307.

28. Kerstein M, Flower M, Harkavy LM, Gross PA. Surveillance for postoperative wound infections: practical aspects. Am Surg 1978;44(4):210-214.

29. Mead PB, Pories SE, Hall P, Vacek PM, Davis JH Jr, Gamelli RL. Decreasing the incidence of surgical wound infections: validation of a surveillance-notification program. Arch Surg 1986; 121(4):458-461.

30. Baker C, Luce J, Chenoweth C, Friedman C. Comparison of case-finding methodologies for endometritis after cesarean section. Am J Infect Control 1995;23(1):27-33.

31. Cardo DM, Falk PS, Mayhall CG. Validation of surgical wound surveillance. Infect Control Hosp Epidemiol 1993;14(4):21 1-215.

32. Ming DY, Chen LF, Miller BA, Anderson DJ. The impact of depth of infection and postdischarge surveillance on rate of surgical-site infections in a network of community hospitals. Infect Control Hosp Epidemiol 2012;33(3):276-282.

33. Chalfine A, Cauet D, Lin WC, et al. Highly sensitive and efficient computer-assisted system for routine surveillance for surgical site infection. Infect Control Hosp Epidemiol 2006;27(8): 794-801.

34. Miner AL, Sands KE, Yokoe DS, et al. Enhanced identification of postoperative infections among outpatients. Emerg Infect Dis 2004;10(11):1931-1937.

35. Yokoe DS, Noskin GA, Cunnigham SM, et al. Enhanced iden- tification of postoperative infections among inpatients. Emerg Infect Dis 2004;10(11):1924-1930.

36. Calderwood MS, Kleinman K, Bratzler DW, et al. Use of Medicare claims to identify US hospitals with a high rate of surgical site infection after hip arthroplasty. Infect Control Hosp Epidemiol 2013;34(1):31-39.

37. Huang SS, Placzek H, Livingston J, et al. Use of Medicare claims to rank hospitals by surgical site infection risk following coronary artery bypass graft surgery. Infect Control Hosp Epidemiol $2011 ; 32(8): 775-783$.

38. Haley VB, Van Antwerpen C, Tserenpuntsag B, et al. Use of administrative data in efficient auditing of hospital-acquired surgical site infections, New York State 2009-2010. Infect Control Hosp Epidemiol 2012;33(6):565-571.

39. Burke JP. Infection control-a problem for patient safety. $N$ Engl J Med 2003;348(7):651-656.

40. Cullen KA, Hall MJ, Golosinkiy A. Ambulatory surgery in the United States, 2006. Natl Health Stat Report 2009;(11):1-25.

41. National action plan to prevent health care-associated infections: roadmap to elimination; ambulatory surgical centers. Department of Health and Human Services website. http:// www.hhs.gov/ash/initiatives/hai/ambulatory_surgical_centers .html. Accessed January 4, 2013.

42. Consensus paper on the surveillance of surgical wound infections. The Society for Hospital Epidemiology of America; the Association for Practitioners in Infection Control; the Centers for Disease Control; the Surgical Infection Society. Infect Control Hosp Epidemiol 1992;13(10):599-605.

43. Mannien J, Wille JC, Snoeren RL, van den Hof S. Impact of postdischarge surveillance on surgical site infection rates for several surgical procedures: results from the nosocomial surveillance network in the Netherlands. Infect Control Hosp Epidemiol 2006;27(8):809-816.

44. Kent P, McDonald M, Harris O, Mason T, Spelman D. Postdischarge surgical wound infection surveillance in a provincial hospital: follow-up rates, validity of data and review of the literature. ANZ J Surg 2001;71(10):583-589.

45. Manian FA. Surveillance of surgical site infections in alternative settings: exploring the current options. Am J Infect Control 1997;25(2):102-105.

46. Michelson J. Improved detection of orthopaedic surgical site infections occurring in outpatients. Clin Orthop Relat Res 2005(433):218-224.

47. Nafziger DA, Lundstrom T, Chandra S, Massanari RM. Infection control in ambulatory care. Infect Dis Clin North Am 1997; 11(2):279-296.

48. Petherick ES, Dalton JE, Moore PJ, Cullum N. Methods for identifying surgical wound infection after discharge from hospital: a systematic review. BMC Infect Dis 2006;6:170.

49. Mlangeni D, Babikir R, Dettenkofer M, Daschner F, Gastmeier P, Ruden H. AMBU-KISS: quality control in ambulatory surgery. Am J Infect Control 2005;33(1):11-14.

50. Whitby M, McLaws ML, Collopy B, et al. Post-discharge surveillance: can patients reliably diagnose surgical wound infections? J Hosp Infect 2002;52(3):155-160.

51. Manian FA, Meyer L. Comparison of patient telephone survey with traditional surveillance and monthly physician questionnaires in monitoring surgical wound infections. Infect Control Hosp Epidemiol 1993;14(4):216-218.

52. Prospero E, Cavicchi A, Bacelli S, Barbadoro P, Tantucci L, 
D’Errico MM. Surveillance for surgical site infection after hospital discharge: a surgical procedure-specific perspective. Infect Control Hosp Epidemiol 2006;27(12):1313-1317.

53. Sands K, Vineyard G, Platt R. Surgical site infections occurring after hospital discharge. J Infect Dis 1996;173(4):963-970.

54. Healthcare-Associated Infection Working Group of the Joint Public Policy Committee. Essentials of Public Reporting of Healthcare-Associated Infections: A Tool Kit. 2007. http://www .shea-online.org/Assets/files/Essentials_of_Public_Reporting _Tool_Kit.pdf. Accessed January 5, 2013.

55. National Quality Forum (NQF). National Voluntary Consensus Standards for the Reporting of Healthcare-Associated Infection Data. Washington, DC: NQF, 2008. http://www.qualityforum .org/Publications/2008/03/National_Voluntary_Consensus _Standards_for_the_Reporting_of_Healthcare-Associated Infection_Data.aspx. Accessed January 6, 2013.

56. National Institute for Health and Clinical Excellence (NICE). Surgical Site Infection: Prevention and Treatment of Surgical Site Infection. London: NICE, 2008. http:/www.nice.org.uk /nicemedia/pdf/CG74NICEGuideline.pdf. Accessed February 12, 2013.

57. Bratzler DW, Houck PM. Antimicrobial prophylaxis for surgery: an advisory statement from the National Surgical Infection Prevention Project. Clin Infect Dis 2004;38(12):1706-1715.

58. Bratzler DW, Hunt DR. The surgical infection prevention and surgical care improvement projects: national initiatives to improve outcomes for patients having surgery. Clin Infect Dis 2006;43(3):322-330.

59. Dellinger EP, Hausmann SM, Bratzler DW, et al. Hospitals collaborate to decrease surgical site infections. Am J Surg 2005; 190(1):9-15.

60. National Quality Forum (NQF). Cardiac Surgery Patients with Controlled Postoperative Blood Glucose. Washington, DC: NQF, 2013. http://www.qualityforum.org/. Accessed January 6, 2013.

61. Lazar HL, McDonnell M, Chipkin SR, et al. The Society of Thoracic Surgeons practice guideline series: blood glucose management during adult cardiac surgery. Ann Thorac Surg 2009;87(2):663-669.

62. A resource from the Institute of Healthcare Improvement. Institute for Healthcare Improvement (IHI) website. http:// www.ihi.org. Accessed January 31, 2007.

63. Griffin FA. Reducing surgical complications. It Comm J Qual Patient Saf 2007;33(11):660-665.

64. The Joint Commission. National Patient Safety Goals Effective January 1, 2013. Oakbrook Terrace, IL: The Joint Commission, 2013. http://www.jointcommission.org/assets/1/18 /NPSG_Chapter_Jan2013_HAP.pdf. Accessed March 1, 2013.

65. Centers for Medicare \& Medicaid Services. Medicare program; hospital inpatient prospective payment systems for acute care hospitals and the long-term care hospital prospective payment system and fiscal year 2013 rates; hospitals' resident caps for graduate medical education payment purposes; quality reporting requirements for specific providers and for ambulatory surgical centers. Final rule. Fed Regist 2012;77(170):5325753750.

66. Centers for Medicare \& Medicaid Services. Medicare program; hospital inpatient value-based purchasing program. Final rule. Fed Regist 2011;76(88):26490-26547.

67. van Kasteren ME, Mannien J, Kullberg BJ, et al. Quality improvement of surgical prophylaxis in Dutch hospitals: evalu- ation of a multi-site intervention by time series analysis. $J$ Antimicrob Chemother 2005;56(6):1094-1102.

68. Schweon S. Stamping out surgical site infections. RN 2006; 69(8):36-40.

69. Torpy JM, Burke A, Glass RM. JAMA patient page: wound infections. JAMA 2005;294(16):2122.

70. Kanter G, Connelly NR, Fitzgerald J. A system and process redesign to improve perioperative antibiotic administration. Anesth Analg 2006;103(6):1517-1521.

71. Pestotnik SL, Classen DC, Evans RS, Burke JP. Implementing antibiotic practice guidelines through computer-assisted decision support: clinical and financial outcomes. Ann Intern Med 1996;124(10):884-890.

72. Webb AL, Flagg RL, Fink AS. Reducing surgical site infections through a multidisciplinary computerized process for preoperative prophylactic antibiotic administration. Am J Surg 2006; 192(5):663-668.

73. Nair BG, Newman SF, Peterson GN, Wu WY, Schwid HA. Feedback mechanisms including real-time electronic alerts to achieve near $100 \%$ timely prophylactic antibiotic administration in surgical cases. Anesth Analg 2010;111(5):1293-1300.

74. Berger RG, Kichak JP. Computerized physician order entry: helpful or harmful? J Am Med Inform Assoc 2004;11(2):100103.

75. Antimicrobial prophylaxis for surgery. Treat Guidel Med Lett 2009;7(82):47-52.

76. Bratzler DW, Dellinger EP, Olsen KM, et al. Clinical practice guidelines for antimicrobial prophylaxis in surgery. Am J Health Syst Pharm 2013;70(3):195-283.

77. Steinberg JP, Braun BI, Hellinger WC, et al. Timing of antimicrobial prophylaxis and the risk of surgical site infections: results from the Trial to Reduce Antimicrobial Prophylaxis Errors. Ann Surg 2009;250(1):10-16.

78. van Kasteren ME, Mannien J, Ott A, Kullberg BJ, de Boer AS, Gyssens IC. Antibiotic prophylaxis and the risk of surgical site infections following total hip arthroplasty: timely administration is the most important factor. Clin Infect Dis 2007;44(7): 921-927.

79. Soriano A, Bori G, Garcia-Ramiro S, et al. Timing of antibiotic prophylaxis for primary total knee arthroplasty performed during ischemia. Clin Infect Dis 2008;46(7):1009-1014.

80. Akinyoola AL, Adegbehingbe OO, Odunsi A. Timing of antibiotic prophylaxis in tourniquet surgery. I Foot Ankle Surg 2011;50(4):374-376.

81. Harbarth S, Samore MH, Lichtenberg D, Carmeli Y. Prolonged antibiotic prophylaxis after cardiovascular surgery and its effect on surgical site infections and antimicrobial resistance. Circulation 2000;101(25):2916-2921.

82. McDonald M, Grabsch E, Marshall C, Forbes A. Single- versus multiple-dose antimicrobial prophylaxis for major surgery: a systematic review. Aust N Z J Surg 1998;68(6):388-396.

83. Coakley BA, Sussman ES, Wolfson TS, et al. Postoperative antibiotics correlate with worse outcomes after appendectomy for nonperforated appendicitis. J Am Coll Surg 2011;213(6):778783.

84. Cannon JA, Altom LK, Deierhoi RJ, et al. Preoperative oral antibiotics reduce surgical site infection following elective colorectal resections. Dis Colon Rectum 2012;55(11):1160-1166.

85. Englesbe MJ, Brooks L, Kubus J, et al. A statewide assessment 
of surgical site infection following colectomy: the role of oral antibiotics. Ann Surg 2010;252(3):514-519.

86. Fry DE. Colon preparation and surgical site infection. Am J Surg 2011;202(2):225-232.

87. Hendren S, Fritze D, Banerjee $M$, et al. Antibiotic choice is independently associated with risk of surgical site infection after colectomy: a population-based cohort study. Ann Surg 2013;257(3):469-475.

88. Lewis RT. Oral versus systemic antibiotic prophylaxis in elective colon surgery: a randomized study and meta-analysis send a message from the 1990s. Can J Surg 2002;45(3):173-180.

89. Nelson RL, Glenny AM, Song F. Antimicrobial prophylaxis for colorectal surgery. Cochrane Database Syst Rev 2009;(1): CD001181.

90. Deierhoi RJ, Dawes LG, Vick C, Itani KM, Hawn MT. Choice of intravenous antibiotic prophylaxis for colorectal surgery does matter. J Am Coll Surg 2013;217(5):763-769.

91. Toneva GD, Deierhoi RJ, Morris M, et al. Oral antibiotic bowel preparation reduces length of stay and readmissions after colorectal surgery. J Am Coll Surg 2013;216(4):756-762.

92. Guenaga KF, Matos D, Wille-Jorgensen P. Mechanical bowel preparation for elective colorectal surgery. Cochrane Database Syst Rev 2011;(9):CD001544.

93. Tanner J, Woodings D, Moncaster K. Preoperative hair removal to reduce surgical site infection. Cochrane Database Syst Rev 2006;(3):CD004122.

94. Dronge AS, Perkal MF, Kancir S, Concato J, Aslan M, Rosenthal RA. Long-term glycemic control and postoperative infectious complications. Arch Surg 2006;141(4):375-380.

95. Golden SH, Peart-Vigilance C, Kao WH, Brancati FL. Perioperative glycemic control and the risk of infectious complications in a cohort of adults with diabetes. Diabetes Care 1999; 22(9):1408-1414.

96. Olsen MA, Nepple JJ, Riew KD, et al. Risk factors for surgical site infection following orthopaedic spinal operations. J Bone Joint Surg Am 2008;90(1):62-69.

97. Kwon S, Thompson R, Dellinger P, Yanez D, Farrohki E, Flum D. Importance of perioperative glycemic control in general surgery: a report from the Surgical Care and Outcomes Assessment Program. Ann Surg 2013;257(1):8-14.

98. Umpierrez GE, Smiley D, Jacobs S, et al. Randomized study of basal-bolus insulin therapy in the inpatient management of patients with type 2 diabetes undergoing general surgery (RABBIT 2 surgery). Diabetes Care 2011;34(2):256-261.

99. Jacobi J, Bircher N, Krinsley J, et al. Guidelines for the use of an insulin infusion for the management of hyperglycemia in critically ill patients. Crit Care Med 2012;40(12):3251-3276.

100. Umpierrez GE, Hellman R, Korytkowski MT, et al. Management of hyperglycemia in hospitalized patients in non-critical care setting: an endocrine society clinical practice guideline. $J$ Clin Endocrinol Metab 2012;97(1):16-38.

101. Gandhi GY, Nuttall GA, Abel MD, et al. Intensive intraoperative insulin therapy versus conventional glucose management during cardiac surgery: a randomized trial. Ann Intern Med 2007;146(4):233-243.

102. Sessler DI. Complications and treatment of mild hypothermia. Anesthesiology 2001;95(2):531-543.

103. Kurz A, Sessler DI, Lenhardt R; Study of Wound Infection and Temperature Group. Perioperative normothermia to reduce the incidence of surgical-wound infection and shorten hospitalization. N Engl J Med 1996;334(19):1209-1215.

104. Melling AC, Ali B, Scott EM, Leaper DJ. Effects of preoperative warming on the incidence of wound infection after clean surgery: a randomised controlled trial. Lancet 2001;358(9285): 876-880.

105. Wong PF, Kumar S, Bohra A, Whetter D, Leaper DJ. Randomized clinical trial of perioperative systemic warming in major elective abdominal surgery. $\mathrm{Br} J$ Surg 2007;94(4):421-426.

106. Belda FJ, Aguilera L, Garcia de la Asuncion J, et al. Supplemental perioperative oxygen and the risk of surgical wound infection: a randomized controlled trial. JAMA 2005;294(16): 2035-2042.

107. Greif R, Akca O, Horn EP, Kurz A, Sessler DI; Outcomes Research Group. Supplemental perioperative oxygen to reduce the incidence of surgical-wound infection. $N$ Engl J Med 2000; 342(3):161-167.

108. Bickel A, Gurevits M, Vamos R, Ivry S, Eitan A. Perioperative hyperoxygenation and wound site infection following surgery for acute appendicitis: a randomized, prospective, controlled trial. Arch Surg 2011;146(4):464-470.

109. Meyhoff CS, Wetterslev J, Jorgensen LN, et al. Effect of high perioperative oxygen fraction on surgical site infection and pulmonary complications after abdominal surgery: the PROXI randomized clinical trial. JAMA 2009;302(14):1543-1550.

110. Pryor KO, Fahey TJ 3rd, Lien CA, Goldstein PA. Surgical site infection and the routine use of perioperative hyperoxia in a general surgical population: a randomized controlled trial. JAMA 2004;291(1):79-87.

111. Schietroma M, Carlei F, Cecilia EM, Piccione F, Bianchi Z, Amicucci G. Colorectal infraperitoneal anastomosis: the effects of perioperative supplemental oxygen administration on the anastomotic dehiscence. J Gastrointest Surg 2012;16(2):427434.

112. Schietroma M, Cecilia EM, Carlei F, et al. Prevention of anastomotic leakage after total gastrectomy with perioperative supplemental oxygen administration: a prospective randomized, double-blind, controlled, single-center trial. Ann Surg Oncol 2013;20(5):1584-1590.

113. Meyhoff CS, Jorgensen LN, Wetterslev J, Christensen KB, Rasmussen LS. Increased long-term mortality after a high perioperative inspiratory oxygen fraction during abdominal surgery: follow-up of a randomized clinical trial. Anesth Analg 2012; 115(4):849-854.

114. Qadan M, Akca O, Mahid SS, Hornung CA, Polk HC Jr. Perioperative supplemental oxygen therapy and surgical site infection: a meta-analysis of randomized controlled trials. Arch Surg 2009;144(4):359-366.

115. Maiwald M, Chan ES. The forgotten role of alcohol: a systematic review and meta-analysis of the clinical efficacy and perceived role of chlorhexidine in skin antisepsis. PloS ONE 2012; $7(9):$ e44277.

116. Darouiche RO, Wall MJ Jr, Itani $\mathrm{KM}$, et al. Chlorhexidinealcohol versus povidone-iodine for surgical-site antisepsis. $N$ Engl J Med 2010;362(1):18-26.

117. Swenson BR, Hedrick TL, Metzger R, Bonatti H, Pruett TL, Sawyer RG. Effects of preoperative skin preparation on postoperative wound infection rates: a prospective study of 3 skin preparation protocols. Infect Control Hosp Epidemiol 2009; 30(10):964-971. 
118. Aly R, Maibach HI. Comparative antibacterial efficacy of a 2minute surgical scrub with chlorhexidine gluconate, povidoneiodine, and chloroxylenol sponge-brushes. Am I Infect Control 1988;16(4):173-177.

119. Larson E. Guideline for use of topical antimicrobial agents. Am J Infect Control 1988;16(6):253-266.

120. Edwards JP, Ho AL, Tee MC, Dixon E, Ball CG. Wound protectors reduce surgical site infection: a meta-analysis of randomized controlled trials. Ann Surg 2012;256(1):53-59.

121. Haynes AB, Weiser TG, Berry WR, et al. A surgical safety checklist to reduce morbidity and mortality in a global population. N Engl J Med 2009;360(5):491-499.

122. Weiser TG, Haynes AB, Dziekan G, Berry WR, Lipsitz SR, Gawande AA. Effect of a 19-item surgical safety checklist during urgent operations in a global patient population. Ann Surg 2010;251(5):976-980.

123. van Klei WA, Hoff RG, van Aarnhem EE, et al. Effects of the introduction of the WHO "Surgical Safety Checklist" on inhospital mortality: a cohort study. Ann Surg 2012;255(1):4449.

124. Haley RW, Culver DH, White JW, et al. The efficacy of infection surveillance and control programs in preventing nosocomial infections in US hospitals. Am J Epidemiol 1985;121(2):182205.

125. Lee JT. Wound infection surveillance. Infect Dis Clin North Am 1992;6(3):643-656.

126. Calderwood MS, Ma A, Khan YM, et al. Use of Medicare diagnosis and procedure codes to improve detection of surgical site infections following hip arthroplasty, knee arthroplasty, and vascular surgery. Infect Control Hosp Epidemiol 2012;33(1):4049.

127. Bolon MK, Hooper D, Stevenson KB, et al. Improved surveillance for surgical site infections after orthopedic implantation procedures: extending applications for automated data. Clin Infect Dis 2009;48(9):1223-1229.

128. Gerbier-Colomban S, Bourjault M, Cetre JC, Baulieux J, Metzger $\mathrm{MH}$. Evaluation study of different strategies for detecting surgical site infections using the hospital information system at Lyon University Hospital, France. Ann Surg 2012;255(5): 896-900.

129. Yokoe DS, Khan Y, Olsen MA, et al. Enhanced surgical site infection surveillance following hysterectomy, vascular, and colorectal surgery. Infect Control Hosp Epidemiol 2012;33(8):768773.

130. Jamtvedt G, Young JM, Kristoffersen DT, O'Brien MA, Oxman AD. Audit and feedback: effects on professional practice and health care outcomes. Cochrane Database Syst Rev 2006;(2): CD000259.

131. Skoufalos A, Clarke JL, Napp M, et al. Improving awareness of best practices to reduce surgical site infection: a multistakeholder approach. Am J Med Qual 2012;27(4):297-304.

132. Association of periOperative Registered Nurses. 2013. http:// www.aorn.org/. Accessed March 23, 2013.

133. Culver DH, Horan TC, Gaynes RP, et al; National Nosocomial Infections Surveillance System. Surgical wound infection rates by wound class, operative procedure, and patient risk index. Am J Med 1991;91(3B):152S-157S.

134. Loftus RW, Brown JR, Koff MD, et al. Multiple reservoirs contribute to intraoperative bacterial transmission. Anesth Analg 2012;114(6):1236-1248.
135. Andersson AE, Bergh I, Karlsson J, Eriksson BI, Nilsson K. Traffic flow in the operating room: an explorative and descriptive study on air quality during orthopedic trauma implant surgery. Am J Infect Control 2012;40(8):750-755.

136. Crolla RM, van der Laan L, Veen EJ, Hendriks Y, van Schendel C, Kluytmans J. Reduction of surgical site infections after implementation of a bundle of care. PloS ONE 2012;7(9):e44599.

137. van Rijen M, Bonten $M$, Wenzel R, Kluytmans J. Mupirocin ointment for preventing Staphylococcus aureus infections in nasal carriers. Cochrane Database Syst Rev 2008;(4):CD006216.

138. Wilcox $\mathrm{MH}$, Hall J, Pike $\mathrm{H}$, et al. Use of perioperative mupirocin to prevent methicillin-resistant Staphylococcus aureus (MRSA) orthopaedic surgical site infections. J Hosp Infect 2003; 54(3):196-201.

139. Nicholson MR, Huesman LA. Controlling the usage of intranasal mupirocin does impact the rate of Staphylococcus aureus deep sternal wound infections in cardiac surgery patients. Am $J$ Infect Control 2006;34(1):44-48.

140. Walsh EE, Greene L, Kirshner R. Sustained reduction in methicillin-resistant Staphylococcus aureus wound infections after cardiothoracic surgery. Arch Intern Med 2011;171(1):68-73.

141. Bode LG, Kluytmans JA, Wertheim HF, et al. Preventing surgical-site infections in nasal carriers of Staphylococcus aureus. N Engl J Med 2010;362(1):9-17.

142. Harbarth S, Fankhauser C, Schrenzel J, et al. Universal screening for methicillin-resistant Staphylococcus aureus at hospital admission and nosocomial infection in surgical patients. JAMA 2008;299(10):1149-1157.

143. Perl TM, Cullen JJ, Wenzel RP, et al. Intranasal mupirocin to prevent postoperative Staphylococcus aureus infections. $N$ Engl $J$ Med 2002;346(24):1871-1877.

144. Schweizer M, Perencevich E, McDanel J, et al. Effectiveness of a bundled intervention of decolonization and prophylaxis to decrease Gram positive surgical site infections after cardiac or orthopedic surgery: systematic review and meta-analysis. $B M J$ 2013;346:f2743.

145. Miller MA, Dascal A, Portnoy J, Mendelson J. Development of mupirocin resistance among methicillin-resistant Staphylococcus aureus after widespread use of nasal mupirocin ointment. Infect Control Hosp Epidemiol 1996;17(12):811-813.

146. Whiteside OJ, Tytherleigh MG, Thrush S, Farouk R, Galland $\mathrm{RB}$. Intra-operative peritoneal lavage-who does it and why? Ann R Coll Surg Engl 2005;87(4):255-258.

147. Fournel I, Tiv M, Soulias M, Hua C, Astruc K, Aho Glele LS. Meta-analysis of intraoperative povidone-iodine application to prevent surgical-site infection. Br J Surg 2010;97(11):16031613.

148. Thompson KM, Oldenburg WA, Deschamps C, Rupp WC, Smith $C D$. Chasing zero: the drive to eliminate surgical site infections. Ann Surg 2011;254(3):430-436.

149. Haessler S, Connelly NR, Kanter G, et al. A surgical site infection cluster: the process and outcome of an investigationthe impact of an alcohol-based surgical antisepsis product and human behavior. Anesth Analg 2010;110(4):1044-1048.

150. Panahi P, Stroh M, Casper DS, Parvizi J, Austin MS. Operating room traffic is a major concern during total joint arthroplasty. Clin Orthop Relat Res 2012;470(10):2690-2694.

151. Tadros MA, Williams VR, Plourde S, Callery S, Simor AE, Vearncombe M. Risk factors for Staphylococcus aureus surgical 
site infection during an outbreak in patients undergoing cardiovascular surgery. Am I Infect Control 2013;41(6):509-512.

152. Wiener-Well Y, Galuty M, Rudensky B, Schlesinger Y, Attias D, Yinnon AM. Nursing and physician attire as possible source of nosocomial infections. Am J Infect Control 2011;39(7):555559.

153. Wright SN, Gerry JS, Busowski MT, et al. Gordonia bronchialis sternal wound infection in 3 patients following open heart surgery: intraoperative transmission from a healthcare worker. Infect Control Hosp Epidemiol 2012;33(12):1238-1241.

154. Kohlenberg A, Weitzel-Kage D, van der Linden P, et al. Outbreak of carbapenem-resistant Pseudomonas aeruginosa infection in a surgical intensive care unit. J Hosp Infect 2010;74(4): 350-357.

155. Siegel JD, Rhinehart E, Jackson M, Chiarello L; Healthcare Infection Control Practices Advisory Committee (HICPAC). Management of Multidrug-Resistant Organisms in Healthcare Settings, 2006. Atlanta: Centers for Disease Control and Prevention, 2006. http://www.cdc.gov/hicpac/pdf/MDRO /MDROGuideline2006.pdf. Accessed January 3, 2014.

156. Dodds Ashley ES, Carroll DN, Engemann JJ, et al. Risk factors for postoperative mediastinitis due to methicillin-resistant Staphylococcus aureus. Clin Infect Dis 2004;38(11):1555-1560.

157. Chambers D, Worthy G, Myers L, et al. Glycopeptide vs. nonglycopeptide antibiotics for prophylaxis of surgical site infections: a systematic review. Surg Infect (Larchmt) 2010;11(5): 455-462.

158. Bolon MK, Morlote M, Weber SG, Koplan B, Carmeli Y, Wright SB. Glycopeptides are no more effective than beta-lactam agents for prevention of surgical site infection after cardiac surgery: a meta-analysis. Clin Infect Dis 2004;38(10):13571363.

159. Bull AL, Worth LJ, Richards MJ. Impact of vancomycin surgical antibiotic prophylaxis on the development of methicillin-sensitive Staphylococcus aureus surgical site infections: report from Australian Surveillance Data (VICNISS). Ann Surg 2012; 256(6):1089-1092.

160. Brennan MF, Pisters PW, Posner M, Quesada O, Shike M. A prospective randomized trial of total parenteral nutrition after major pancreatic resection for malignancy. Ann Surg 1994; $220(4): 436-441$.

161. Veterans Affairs Total Parenteral Nutrition Cooperative Study Group. Perioperative total parenteral nutrition in surgical patients. N Engl J Med 1991;325(8):525-532.

162. Marimuthu $\mathrm{K}$, Varadhan $\mathrm{KK}$, Ljungqvist $\mathrm{O}$, Lobo DN. A metaanalysis of the effect of combinations of immune modulating nutrients on outcome in patients undergoing major open gastrointestinal surgery. Ann Surg 2012;255(6):1060-1068.

163. Zhang Y, Gu Y, Guo T, Li Y, Cai H. Perioperative immunonutrition for gastrointestinal cancer: a systematic review of randomized controlled trials. Surg Oncol 2012;21(2):e87-e95.

164. Elek SD, Conen PE. The virulence of Staphylococcus pyogenes for man: a study of the problems of wound infection. Br J Exp Pathol 1957;38(6):573-586.

165. Nakamura T, Kashimura N, Noji T, et al. Triclosan-coated sutures reduce the incidence of wound infections and the costs after colorectal surgery: a randomized controlled trial. Surgery 2013;153(4):576-583.

166. Chang WK, Srinivasa S, Morton R, Hill AG. Triclosanimpregnated sutures to decrease surgical site infections: sys- tematic review and meta-analysis of randomized trials. Ann Surg 2012;255(5):854-859.

167. Deliaert AE, Van den Kerckhove E, Tuinder S, et al. The effect of triclosan-coated sutures in wound healing: a double blind randomised prospective pilot study. J Plast Reconstr Aesthet Surg 2009;62(6):771-773.

168. Webster J, Alghamdi AA. Use of plastic adhesive drapes during surgery for preventing surgical site infection. Cochrane Database Syst Rev 2007;(4):CD006353.

169. Cordtz T, Schouenborg L, Laursen $K$, et al. The effect of incisional plastic drapes and redisinfection of operation site on wound infection following caesarean section. J Hosp Infect 1989;13(3):267-272.

170. Dewan PA, Van Rij AM, Robinson RG, Skeggs GB, Fergus M. The use of an iodophor-impregnated plastic incise drape in abdominal surgery-a controlled clinical trial. Aust N Z J Surg 1987;57(11):859-863.

171. Segal CG, Anderson JJ. Preoperative skin preparation of cardiac patients. AORN J 2002;76(5):821-828.

172. Swenson BR, Camp TR, Mulloy DP, Sawyer RG. Antimicrobialimpregnated surgical incise drapes in the prevention of mesh infection after ventral hernia repair. Surg Infect (Larchmt) 2008; 9(1):23-32.

173. Kaul AF, Jewett JF. Agents and techniques for disinfection of the skin. Surg Gynecol Obstet 1981;152(5):677-685.

174. Webster J, Osborne S. Preoperative bathing or showering with skin antiseptics to prevent surgical site infection. Cochrane Database Syst Rev 2007;(2):CD004985.

175. Edmiston CE Jr, Krepel CJ, Seabrook GR, Lewis BD, Brown KR, Towne JB. Preoperative shower revisited: can high topical antiseptic levels be achieved on the skin surface before surgical admission? J Am Coll Surg 2008;207(2):233-239.

176. Eiselt D. Presurgical skin preparation with a novel $2 \%$ chlorhexidine gluconate cloth reduces rates of surgical site infection in orthopaedic surgical patients. Orthop Nurs 2009;28(3):141145.

177. Segers P, Speekenbrink RG, Ubbink DT, van Ogtrop ML, de $\mathrm{Mol}$ BA. Prevention of nosocomial infection in cardiac surgery by decontamination of the nasopharynx and oropharynx with chlorhexidine gluconate: a randomized controlled trial. JAMA 2006;296(20):2460-2466.

178. de Bruin AF, Gosselink MP, van der Harst E, Rutten HJ. Local application of gentamicin collagen implants in the prophylaxis of surgical site infections following gastrointestinal surgery: a review of clinical experience. Tech Coloproctol 2010;14(4):301310.

179. Guzmán Valdivia Gomez G, Guerrero TS, Lluck MC, Delgado FJ. Effectiveness of collagen-gentamicin implant for treatment of "dirty" abdominal wounds. World J Surg 1999;23(2):123126.

180. Rutten HJ, Nijhuis PH. Prevention of wound infection in elective colorectal surgery by local application of a gentamicincontaining collagen sponge. Eur J Surg Suppl 1997;(578):3135.

181. Bennett-Guerrero E, Pappas TN, Koltun WA, et al. Gentamicin-collagen sponge for infection prophylaxis in colorectal surgery. $N$ Engl J Med 2010;363(11):1038-1049.

182. Eklund AM, Valtonen M, Werkkala KA. Prophylaxis of sternal wound infections with gentamicin-collagen implant: random- 
ized controlled study in cardiac surgery. $J$ Hosp Infect 2005; 59(2):108-112.

183. Friberg O, Svedjeholm R, Soderquist B, Granfeldt $H$, Vikerfors T, Kallman J. Local gentamicin reduces sternal wound infections after cardiac surgery: a randomized controlled trial. Ann Thorac Surg 2005;79(1):153-161.

184. Schimmer C, Ozkur M, Sinha B, et al. Gentamicin-collagen sponge reduces sternal wound complications after heart surgery: a controlled, prospectively randomized, double-blind study. J Thorac Cardiovasc Surg 2012;143(1):194-200.

185. Bennett-Guerrero E, Ferguson TB Jr, Lin M, et al. Effect of an implantable gentamicin-collagen sponge on sternal wound infections following cardiac surgery: a randomized trial. JAMA 2010;304(7):755-762.

186. Mavros MN, Mitsikostas PK, Alexiou VG, Peppas G, Falagas ME. Gentamicin collagen sponges for the prevention of sternal wound infection: a meta-analysis of randomized controlled trials. J Thorac Cardiovasc Surg 2012;144(5):1235-1240.

187. Anthony T, Murray BW, Sum-Ping JT, et al. Evaluating an evidence-based bundle for preventing surgical site infection: a randomized trial. Arch Surg 2011;146(3):263-269.

188. Young-Xu Y, Neily J, Mills PD, et al. Association between implementation of a medical team training program and surgical morbidity. Arch Surg 2011;146(12):1368-1373.

189. Malpiedi PJ, Peterson KD, Soe MM, et al. 2011 National and State Healthcare-Associated Infection Standardized Infection Ratio Report. Atlanta: National Center for Emerging and Zoonotic Infectious Diseases, 2013. http://www.cdc.gov/hai/pdfs/SIR /SIR-Report_02_07_2013.pdf. Accessed May 13, 2013.

190. Mu Y, Edwards JR, Horan TC, Berríos-Torres SI, Fridkin SK. Improving risk-adjusted measures of surgical site infection for the national healthcare safety network. Infect Control Hosp Epidemiol 2011;32(10):970-986.

191. Gaynes RP, Solomon S. Improving hospital-acquired infection rates: the CDC experience. Jt Comm J Qual Improv 1996;22(7): $457-467$.

192. Moehring RW, Anderson DJ. "But my patients are different!": risk adjustment in 2012 and beyond. Infect Control Hosp Epidemiol 2011;32(10):987-989.

193. Berríos-Torres SI, Mu Y, Edwards JR, Horan TC, Fridkin SK. Improved risk adjustment in public reporting: coronary artery bypass graft surgical site infections. Infect Control Hosp Epidemiol 2012;33(5):463-469.

194. Wong ES, Rupp ME, Mermel L, et al. Public disclosure of healthcare-associated infections: the role of the Society for Healthcare Epidemiology of America. Infect Control Hosp Epidemiol 2005;26(2):210-212.

195. McKibben L, Horan T, Tokars JI, et al. Guidance on public reporting of healthcare-associated infections: recommendations of the Healthcare Infection Control Practices Advisory Committee. Am J Infect Control 2005;33(4):217-226.

196. Medicare program; hospital inpatient prospective payment systems for acute care hospitals and the long-term care hospital prospective payment system and FY 2012 rates; hospitals' FTE resident caps for graduate medical education payment. Final rules. Fed Regist 2011;76(160):51476-51846.

197. Medicare program; hospital outpatient prospective payment system and CY 2007 payment rates; CY 2007 update to the ambulatory surgical center covered procedures list; Medicare administrative contractors; and reporting hospital quality data for FY 2008 inpatient prospective payment system annual payment update program-HCAHPS survey, SCIP, and mortality. Final rule with comment period and final rule. Fed Regist 2006; 71(226):67959-68401.

198. National Center for Emerging and Zoonotic Infectious Diseases (NCEZID). Operational Guidance for Reporting Surgical Site Infection (SSI) Data to CDC's NHSN for the Purpose of Fulfilling CMS's Hospital Inpatient Quality Reporting (IQR) Program Requirements. Atlanta: NCEZID, 2012. http://www.cdc.gov/nhsn /PDFs/FINAL-ACH-SSI-Guidance.pdf. Accessed March 29, 2013.

199. Pronovost PJ, Berenholtz SM, Needham DM. Translating evidence into practice: a model for large scale knowledge translation. BMJ 2008;337:a1714.

200. Wick EC, Hobson DB, Bennett JL, et al. Implementation of a surgical comprehensive unit-based safety program to reduce surgical site infections. $J$ Am Coll Surg 2012;215(2):193-200.

201. Ritter MA, French ML, Eitzen HE, Gioe TJ. The antimicrobial effectiveness of operative-site preparative agents: a microbiological and clinical study. J Bone Joint Surg Am 1980;62(5):826828.

202. The Joint Commission. Joint Commission Center for Transforming Healthcare: Reducing Colorectal Surgical Site Infections. Oakbrook Terrace, IL: The Joint Commission, 2013. http://www .centerfortransforminghealthcare.org/assets/4/6/SSI _storyboard.pdf. Accessed August 19, 2013.

203. The Joint Commission. The Joint Commission's Implementation Guide for NPSG.07.05.01 on Surgical Site Infections: The SSI Change Project. Oakbrook Terrace, IL: The Joint Commission, 2013. http://www.jointcommission.org/implementation_guide _for_npsg070501_ssi_change_project/. Accessed August 19, 2013.

204. Ballard MR, Miller NH, Nyquist AC, Elise B, Baulesh DM, Erickson MA. A multidisciplinary approach improves infection rates in pediatric spine surgery. I Pediatr Orthop 2012;32(3): 266-270.

205. Cima R, Dankbar E, Lovely J, et al. Colorectal surgery surgical site infection reduction program: a national surgical quality improvement program-driven multidisciplinary single-institution experience. I Am Coll Surg 2013;216(1):23-33.

206. Hranjec T, Swenson BR, Sawyer RG. Surgical site infection prevention: how we do it. Surg Infect (Larchmt) 2010;11(3): 289-294.

207. Jain M, Miller L, Belt D, King D, Berwick DM. Decline in ICU adverse events, nosocomial infections and cost through a quality improvement initiative focusing on teamwork and culture change. Qual Saf Health Care 2006;15(4):235-239.

208. Alexander JW, Solomkin JS, Edwards MJ. Updated recommendations for control of surgical site infections. Ann Surg 2011;253(6):1082-1093.

209. Hendren S, Englesbe MJ, Brooks L, Kubus J, Yin H, Campbell DA Jr. Prophylactic antibiotic practices for colectomy in Michigan. Am J Surg 2011;201(3):290-293.

210. Riley MM, Suda D, Tabsh K, Flood A, Pegues DA. Reduction of surgical site infections in low transverse cesarean section at a university hospital. Am J Infect Control 2012;40(9):820-825.

211. Lipke VL, Hyott AS. Reducing surgical site infections by bundling multiple risk reduction strategies and active surveillance. AORN J 2010;92(3):288-296.

212. Schwann NM, Bretz KA, Eid S, et al. Point-of-care electronic 
prompts: an effective means of increasing compliance, demonstrating quality, and improving outcome. Anesth Analg 2011; $113(4): 869-876$

213. Berenguer CM, Ochsner MG Jr, Lord SA, Senkowski CK. Improving surgical site infections: using National Surgical Quality Improvement Program data to institute Surgical Care Improvement Project protocols in improving surgical outcomes. $J$ Am Coll Surg 2010;210(5):737-741.

214. Kestle JR, Riva-Cambrin J, Wellons JC 3rd, et al. A standardized protocol to reduce cerebrospinal fluid shunt infection: the Hydrocephalus Clinical Research Network Quality Improvement Initiative. J Neurosurg Pediatr 2011;8(1):22-29.

215. Horan TC, Gaynes RP, Martone WJ, Jarvis WR, Emori TG. CDC definitions of nosocomial surgical site infections, 1992: a modification of CDC definitions of surgical wound infections. Infect Control Hosp Epidemiol 1992;13(10):606-608.

216. Kaye KS, Schmit K, Pieper C, et al. The effect of increasing age on the risk of surgical site infection. J Infect Dis 2005; 191(7):1056-1062.

217. Pessaux P, Msika S, Atalla D, Hay JM, Flamant Y. Risk factors for postoperative infectious complications in noncolorectal abdominal surgery: a multivariate analysis based on a prospective multicenter study of 4718 patients. Arch Surg 2003;138(3):314324.

218. Raymond DP, Pelletier SJ, Crabtree TD, Schulman AM, Pruett TL, Sawyer RG. Surgical infection and the aging population. Am Surg 2001;67(9):827-832.

219. Olsen MA, Lefta M, Dietz JR, et al. Risk factors for surgical site infection after major breast operation. J Am Coll Surg 2008; 207(3):326-335.

220. Faraday N, Rock P, Lin EE, et al. Past history of skin infection and risk of surgical site infection after elective surgery. Ann Surg 2013;257(1):150-154.

221. Forse RA, Karam B, MacLean LD, Christou NV. Antibiotic prophylaxis for surgery in morbidly obese patients. Surgery 1989;106(4):750-756.

222. Hawn MT, Houston TK, Campagna EJ, et al. The attributable risk of smoking on surgical complications. Ann Surg 2011; 254(6):914-920.

223. Moller AM, Pedersen T, Villebro N, Munksgaard A. Effect of smoking on early complications after elective orthopaedic surgery. J Bone Joint Surg Br 2003;85(2):178-181.

224. Moller AM, Villebro N, Pedersen T, Tonnesen H. Effect of preoperative smoking intervention on postoperative complications: a randomised clinical trial. Lancet 2002;359(9301):114117.
225. Sharma A, Deeb AP, Iannuzzi JC, Rickles AS, Monson JR, Fleming FJ. Tobacco smoking and postoperative outcomes after colorectal surgery. Ann Surg 2013;258(2):296-300.

226. Theadom A, Cropley M. Effects of preoperative smoking cessation on the incidence and risk of intraoperative and postoperative complications in adult smokers: a systematic review. Tob Control 2006;15(5):352-358.

227. Hennessey DB, Burke JP, Ni-Dhonochu T, Shields C, Winter DC, Mealy K. Preoperative hypoalbuminemia is an independent risk factor for the development of surgical site infection following gastrointestinal surgery: a multi-institutional study. Ann Surg 2010;252(2):325-329.

228. Boyce JM, Pittet D; Society for Healthcare Epidemiology of America, Association for Professionals in Infection Control, Infectious Diseases Society of America. Guideline for hand hygiene in health-care settings: recommendations of the Healthcare Infection Control Practices Advisory Committee and the HICPAC/SHEA/APIC/IDSA Hand Hygiene Task Force. MMWR Recomm Rep 2002;51(RR-16):1-45.

229. Ford CD, VanMoorleghem G, Menlove RL. Blood transfusions and postoperative wound infection. Surgery 1993;113(6):603607.

230. Horvath KA, Acker MA, Chang $\mathrm{H}$, et al. Blood transfusion and infection after cardiac surgery. Ann Thorac Surg 2013; 95(6):2194-2201.

231. Olsen MA, Lock-Buckley P, Hopkins D, Polish LB, Sundt TM, Fraser VJ. The risk factors for deep and superficial chest surgical-site infections after coronary artery bypass graft surgery are different. $J$ Thorac Cardiovasc Surg 2002;124(1):136-145.

232. Facility Guidelines Institute (FGI) Guidelines. ANSI/ASHRAE/ ASHE Standard 170: Ventilation of Health Care Facilities. Dallas: FGI, 2010. http://www.fgiguidelines.org/guidelines2010.php. Accessed February 2, 2013.

233. Rutala WA, Weber DJ; Healthcare Infection Control Practices Advisory Committee (HICPAC). Guideline for Disinfection and Sterilization in Healthcare Facilities, 2008. Atlanta: Centers for Disease Control and Prevention, 2008. http://www.cdc.gov /hicpac/pdf/guidelines/disinfection_nov_2008.pdf. Accessed December 1, 2013.

234. Guyatt GH, Oxman AD, Vist GE, et al. GRADE: an emerging consensus on rating quality of evidence and strength of recommendations. BMJ 2008;336(7650):924-926.

235. GRADE. Canadian Task Force on Preventive Health Care website. http://canadiantaskforce.ca/methods/grade/. Accessed December 31, 2013. 